\title{
Theoretical framework to estimate spatial rainfall averages conditional on river discharges and point rainfall measurements from a single location: an application to western Greece
}

\author{
A. Langousis and V. Kaleris \\ Department of Civil Engineering, University of Patras, Patras, Greece \\ Correspondence to: A. Langousis (andlag@alum.mit.edu)
}

Received: 22 October 2012 - Published in Hydrol. Earth Syst. Sci. Discuss.: 5 November 2012

Revised: 25 January 2013 - Accepted: 1 March 2013 - Published: 22 March 2013

\begin{abstract}
We focus on the special case of catchments covered by a single rain gauge and develop a theoretical framework to obtain estimates of spatial rainfall averages conditional on rainfall measurements from a single location, and the flow conditions at the catchment outlet. In doing so we use (a) statistical tools to identify and correct inconsistencies between daily rainfall occurrence and amount and the flow conditions at the outlet of the basin; (b) concepts from multifractal theory to relate the fraction of wet intervals in point rainfall measurements and that in spatial rainfall averages, while accounting for the shape and size of the catchment, the size, lifetime and advection velocity of rainfallgenerating features and the location of the rain gauge inside the basin; and (c) semi-theoretical arguments to assure consistency between rainfall and runoff volumes at an interannual level, implicitly accounting for spatial heterogeneities of rainfall caused by orographic influences. In an application study, using point rainfall records from the Glafkos river basin in western Greece, we find the suggested approach to demonstrate significant skill in resolving rainfall-runoff incompatibilities at a daily level, while reproducing the statistics of spatial rainfall averages at both monthly and annual time scales, independent of the location of the rain gauge and the magnitude of the observed deviations between point rainfall measurements and spatial rainfall averages. The developed scheme should serve as an important tool for the effective calibration of rainfall-runoff models in basins covered by a single rain gauge and, also, improve hydrologic impact assessment at a river basin level under changing climatic conditions.
\end{abstract}

\section{Introduction}

For many hydrological applications, such as calibration of rainfall-runoff models, estimation of river discharges $Q(t)$ at the outlet of a basin and quantification of runoff extremes, one needs to calculate spatial averages of daily precipitation. A frequently used estimator for the spatially averaged rainfall intensity $\bar{I}(t)$ over a basin is

$\hat{\bar{I}}(t)=\sum_{j=1}^{s} c_{j} I_{j}(t)$,

where $I_{j}(t)$ is the average rainfall intensity on day $t$ at location $j=1, \ldots, s$ inside the basin, and $c_{j}(j=1, \ldots, s)$ are strictly positive weighting coefficients that sum to 1 . One can obtain $c_{j}(j=1, \ldots, s)$ using a simple method based on Thiessen polygons (Thiessen, 1911, and more recently, Eagleson, 1970; Shaw, 1983; Chow et al., 1988; Singh, 1992) or Kriging (Krige, 1951, and more recently Journel and Huijbregts, 1978; Isaaks and Srivastava, 1989; Banerjee et al., 2004; Press et al., 2007; Koutsoyiannis and Langousis, 2011), or alternatively apply equal weights. In the latter case $c_{j}=1 / s$ for any $j$. The accuracy of the estimator in Eq. (1) increases with increasing number $s$ of the measuring locations inside the basin.

In many cases, however, obtaining an accurate estimate of $\bar{I}(t)$ solely from point rainfall measurements using Eq. (1) is not possible. This can be caused by measurement errors, incompleteness of the historical records and topographic influences or, more frequently, by the low density of measuring locations inside the basin; see e.g. Hutchinson (1970), Willmott et al. (1994), Gebremichael and Krajewski (2004), 

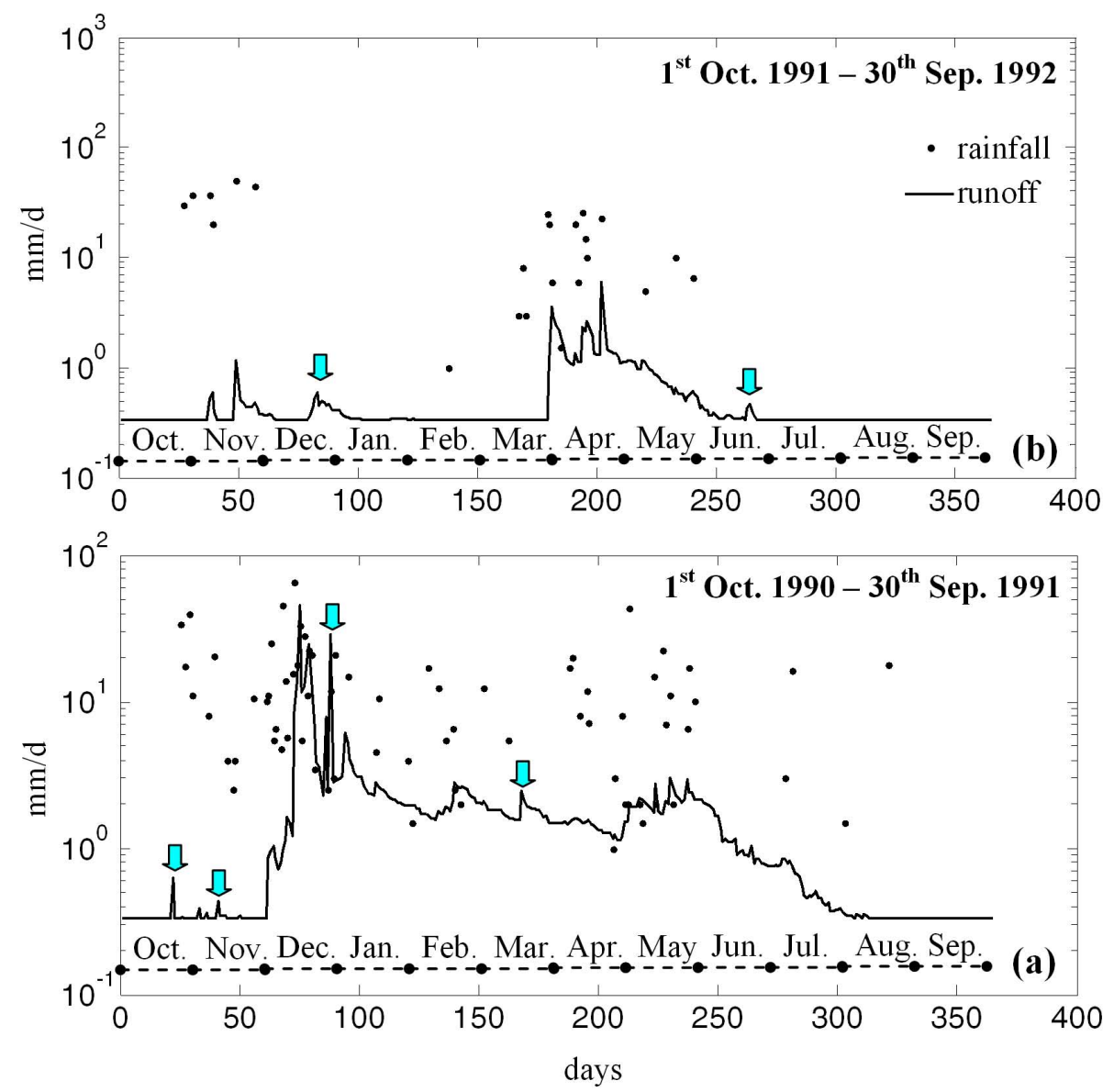

Fig. 1. Measured precipitation depths and daily river discharges per unit area of the basin at the location of the hydroelectric plant (HP, point A in Fig. 2) for the period 1 October 1990-30 September 1992. Vertical arrows indicate abrupt changes of the river discharge in the absence of rain.

Langousis (2005), Veneziano and Langousis (2005a) and Veneziano et al. (2006). The latter is an important issue for many catchments in Greece, and other countries in the Mediterranean region, which causes important problems in the calculation of annual water budgets and the calibration of hydrological models.

In what follows, we focus on the special case of catchments covered by a single rain gauge (i.e. $j=s=1$ ). In this case $\hat{\bar{I}}=I_{1}=I$ and Eq. (1) approximates spatial rainfall averages over the basin using rainfall measurements at a single location. This approximation has well-known limitations originating from the highly variable and lacunar character of rainfall fields (see Smith, 1993; Lovejoy and Schertzer, 1995; Veneziano and Langousis, 2010; Koutsoyiannis and Langousis, 2011, among others), which causes the process of spatial rainfall averages to differ significantly from that of point rainfall measurements; see e.g. Langousis (2005), Veneziano and Langousis (2005a), Veneziano et al. (2006), and Eleuch et al. (2010).
To prove this argument theoretically, it suffices to note that for spatially intermittent rainfall intensity fields and finite sized catchments $P[\bar{I}(t)>0 \mid I(t)=0]>0$ and, therefore, $P[\bar{I}(t)>0]>P[I(t)>0]$. Note that the difference $P[\bar{I}(t)>0]-P[I(t)>0]$ increases with increasing catchment size.

The latter inequality highlights an important issue that emerges when approximating spatial rainfall averages over a catchment using point rainfall measurements. This is the underestimation of the fraction of wet intervals of the spatially averaged rainfall series which leads to incompatibilities between rainfall occurrences and observed changes of the daily river runoff. Another issue concerns the observed imbalances in annual water budgets, caused by the underestimation of the fraction of wet intervals, as well as orographic influences.

To illustrate the first issue, Fig. 1 compares the time series of daily river discharges at the outlet of the Glafkos river basin in western Greece (see Sect. 2) to measured precipitation depths at a single location (point A in Fig. 2) for the period 1 October 1990-30 September 1992. Base flow variations and snowmelt may cause the flow conditions at the 
outlet of the catchment to vary somewhat, but abrupt and intense changes of the river discharge should be associated with rainfall events. The vertical arrows in Fig. 1 indicate such changes in the absence of rain.

Table 1 shows annual precipitation depths and river discharges per unit area of the basin for the hydrological years (i.e. 1 October-30 September) 1974-1993. Note that for hydrological years 1975-1976, 1978-1979, 1979-1980, 19811982 and $1985-1986$, the annual runoff volume is higher than that of precipitation. In addition, for all years on record, the readily available volume of water for evapotranspiration (ET) (i.e. precipitation - runoff) is significantly lower than the ET-estimates reported in the literature for the wider region of the Glafkos catchment; see Voudouris (1995), Nikas (2004) and Mandilaras (2005). The latter are on the order of $500 \mathrm{~mm}$ per year. In the absence of physical indications for groundwater inflow from adjacent catchments (Kaleris and Ziogas, 2011), the aforementioned water imbalances can be attributed to incompatibilities between the historical point rainfall and runoff time series.

A rather straightforward way to correct the available point rainfall series and ensure consistency between annual rainfall and river discharge volumes is to (1) calibrate a hydrological model using the historical rainfall and river discharge data, (2) calculate the difference $\Delta \mathrm{RO}$ between measured and simulated annual runoffs, (3) adjust daily rainfall data using a multiplicative factor, calculated as the ratio between $\Delta \mathrm{RO}$ and the measured annual precipitation depth, and (4) repeat steps 1-3 using the adjusted rainfall series; see Kaleris and Ziogas (2011). The suggested approach can be seen as an extension of the Parsons (or Sacramento) method developed in 1941 at the Corps of Engineers District Office in Sacramento (see US Army Corps of Engineers, 1941, and more recently Gilman, 1964) to determine mean annual precipitation in orographic areas. The Parsons method uses measurements of precipitation and runoff, as well as qualitative knowledge on soil and vegetation, to construct mean annual precipitation maps that minimize annual water imbalances in hydrological budgets.

While simple, the approach of Kaleris and Ziogas (2011) exhibits several intrinsic limitations. One is related to the fact that the hydrological model is calibrated using the original point rainfall records that are subject to adjustments. Hence, the level of the imposed correction and the quality and effectiveness of model calibration are strictly coupled.

Other, more theoretically oriented limitations relate to differences between the statistical characteristics of spatial rainfall averages, which drive river flow and determine annual discharge volumes, and those of point rainfall measurements (see e.g. Eleuch et al., 2010). The latter can be seen as noisy observations of the former. For example, while a constant multiplicative correction factor may ensure consistency between annual rainfall and river discharge volumes, it does not resolve incompatibilities between daily rainfall occurrence and flow conditions at the outlet of the catchment (see Fig. 1).
Table 1. Annual precipitation depths and river discharges per unit area of the basin at the location of the hydroelectric plant (HP, point A in Fig. 2) for the period 1 October 197430 September 1993.

\begin{tabular}{|c|c|c|c|}
\hline $\begin{array}{c}\text { Hydrological } \\
\text { year } \\
\text { (1) }\end{array}$ & $\begin{array}{c}\text { Measured } \\
\text { annual } \\
\text { precipitation } \\
(\mathrm{mm}) \\
(2)\end{array}$ & $\begin{array}{l}\text { Measured } \\
\text { annual } \\
\text { runoff } \\
(\mathrm{mm}) \\
(3)\end{array}$ & (2)-(3) \\
\hline $74-75$ & 595.0 & 536.3 & 58.7 \\
\hline $75-76$ & 609.9 & 686.0 & -76.1 \\
\hline $76-77$ & 710.7 & 678.2 & 32.5 \\
\hline $77-78$ & 1097.9 & 1093.5 & 4.4 \\
\hline $78-79$ & 969.2 & 1086.9 & -117.7 \\
\hline $79-80$ & 1096.0 & 1346.5 & -250.5 \\
\hline $80-81$ & 1029.7 & 892.9 & 136.8 \\
\hline $81-82$ & 976.8 & 1191.0 & -214.2 \\
\hline $82-83$ & 892.1 & 691.2 & 200.9 \\
\hline $83-84$ & 874.1 & 786.2 & 87.8 \\
\hline $84-85$ & 598.1 & 519.3 & 78.8 \\
\hline $85-86$ & 865.2 & 916.9 & -51.7 \\
\hline $86-87$ & 755.6 & 692.5 & 63.2 \\
\hline $87-88$ & 671.1 & 571.1 & 99.9 \\
\hline $88-89$ & 572.3 & 296.7 & 275.6 \\
\hline 89-90 & 496.3 & 220.6 & 275.8 \\
\hline $90-91$ & 901.2 & 630.1 & 271.1 \\
\hline $91-92$ & 409.1 & 188.7 & 220.4 \\
\hline $92-93$ & 532.5 & 251.1 & 281.3 \\
\hline
\end{tabular}

In addition, such correction alters the distribution of rainfall intensities inside wet intervals without changing the fraction of dry intervals. In essence, the resulting time series do not resemble the structure of spatial rainfall averages. As previously outlined, the latter exhibit a lower fraction of dry intervals relative to rainfall measurements at distinct locations inside the catchment.

A theoretically more appealing approach to ensure consistency between recorded rainfall and river discharges is to adjust point rainfall measurements to better resemble the statistical structure of spatial rainfall averages at a daily level and, also, be consistent with the measured discharges at both daily and inter-annual levels.

In the next sections we propose a theoretical framework that uses rainfall data from a single rain gauge to obtain estimates of spatial rainfall averages over a catchment conditional on the same- and previous-day discharges at the outlet. Consistency between the obtained estimates and observed runoffs is sought at both daily and inter-annual time scales.

The developed scheme should serve as an important tool for the effective calibration of rainfall-runoff models in basins covered by a single rain gauge (a frequent case for many catchments in Greece and other countries in the Mediterranean region), which is of particular importance when studying the impacts of climate change on river basin 


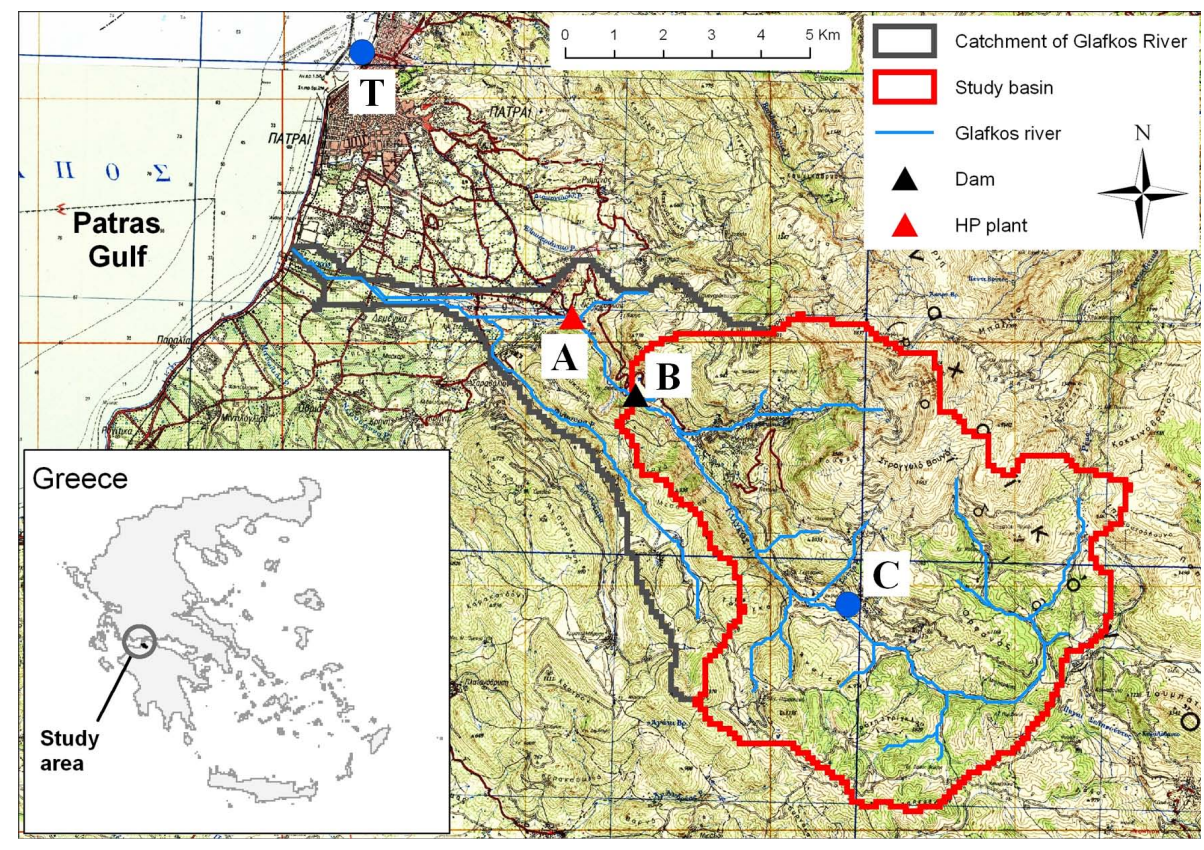

Fig. 2. The catchment of the Glafkos river in West Greece; see Sect. 2 for details.

hydrology, the quality and availability of water resources in space and time, and the sustainability of the natural environment; see e.g. Kaleris et al. (2001) and Wilby et al. (2006). In Europe, the issues of water resource quality, availability and management have officially been stressed by the Water Framework Directive (WFD) 2000/60/EC of the European Parliament and of the Council on 23 October 2000.

The analysis is conducted using daily rainfall data and river discharges from the Glafkos river basin in western Greece. Temperature measurements do not enter the analysis, but they are used in Sect. 5 to obtain estimates of the actual evapotranspiration height in the basin. More details on the available data are given in Sect. 2.

Sections 3 and 4 present the theoretical framework of the suggested methodology. In Sect. 3 we develop a statistical approach to identify and correct inconsistencies between daily rainfall occurrence and amount at the location of the rain gauge and the observed flow conditions at the outlet of the basin. Rainfall occurrence is checked using a statistical test based on the concept of linear reservoirs for river discharges (see Sect. 3.1), whereas daily rainfall intensities are modeled using a lognormal distribution with parameters that depend on the same- and previous-day discharge conditions at the outlet of the catchment (see Sect. 3.2).

As noted above, the fraction of wet intervals in spatial rainfall averages differs from that observed in point rainfall measurements. In Sect. 4 we use concepts from multifractal theory to relate the fraction of wet intervals in point rainfall, $P_{1}$, to that observed in spatial rainfall averages, $\bar{P}_{1}$, while accounting for the shape and size of the basin, the characteristics of rainfall-generating features (size, lifetime and advection velocity vector), and the location of the rain gauge relative to the centroid of the basin (see Sect. 4.2). Since $\bar{P}_{1}>P_{1}$ (see above), several "dry" days in the record of point rainfall measurements should be transformed to "wet". Selection of those days is done conditional on the daily changes of the river discharge.

Section 5 focuses on the inter-annual consistency between rainfall measurements at a point and river discharges at the outlet of the basin and suggests a semi-theoretical approach to resolve water budget imbalances at an inter-annual level, implicitly accounting for spatial heterogeneities of rainfall (see Gilman, 1964; Smith, 1979; 1993 and Koutsoyiannis and Langousis, 2011 among others).

In Sect. 6 we apply and validate the efficiency of the method in resolving rainfall-runoff incompatibilities at both daily and annual time scales. A discussion of the main findings of this work as well as extensions and modifications of the suggested methodology for application to different climates and catchment sizes are presented in Sect. 7.

\section{Available data}

The watershed of the Glafkos river is shown in Fig. 2. It extends from the coast of the Gulf of Patras to the slope of the Panachaikon Mountain. The highest altitude of the catchment is about $1800 \mathrm{~m}$ (a.m.s.l.). In what follows, we focus on the upper mountainous part of the catchment, with outlet at the dam of Glafkos (point B in Fig. 2). The area of this part of the catchment is $65.62 \mathrm{~km}^{2}$, and its water is used for energy production, the water supply of the city of Patras and irrigation. 
Table 2. Physiographic properties of the study basin. The concentration time $t_{\mathrm{c}}$ has been calculated using the method of Watt and Chow (1985); see also Loukas and Quick (1996) and Dingman (2002).

\begin{tabular}{ll}
\hline Area & $65.62 \mathrm{~km}^{2}$ \\
\hline Maximum elevation (a.m.s.1.) & $1800 \mathrm{~m}$ \\
Mean elevation (a.m.s.1.) & $1060 \mathrm{~m}$ \\
Average slope of the study basin & $30 \%$ \\
Average slope of the main stream & $6 \%$ \\
Length of the main channel & $16 \mathrm{~km}$ \\
Estimated concentration time & $3.5 \mathrm{~h}$ \\
\hline
\end{tabular}

The hydroelectric plant (HP) is located downstream from the dam at a distance of about $2 \mathrm{~km}$ (point A in Fig. 2). Several physiographic properties of the study basin are summarized in Table 2.

\subsection{Precipitation time series}

Daily precipitation measurements are available by the Public Power Corporation (PPC) at three locations: (1) the dam (point B in Fig. 2), (2) the hydroelectric plant (HP) (point A in Fig. 2), and (3) the station of PPC at Moira (point $\mathrm{C}$ in Fig. 2). Station $B$ is located at the outlet of the basin at an altitude of $340 \mathrm{~m}$ (a.m.s.l.), station A is located about $2 \mathrm{~km}$ downstream from station B at an altitude of $181 \mathrm{~m}$, and station $\mathrm{C}$ is located close to the centroid of the basin at an altitude of $840 \mathrm{~m}$ (a.m.s.l.). For stations A and B, daily rainfall measurements are available for the period 1 October 1974 to 30 September 1993 (19yr), whereas for station C for the period 1 October 1975 to 30 September 1994 (19 yr).

The available records at stations A (hydroelectric plant, HP) and B (dam) are complete, whereas the rainfall record at station $\mathrm{C}$ exhibits some missing values as shown in Table 3. For the period 1 October 1976 to 30 September 1993, the missing values have been completed by simple averaging of the corresponding daily rainfall measurements at stations A and B, whereas the period 1 October 1993 to 30 September 1994, where no measurements are reported at stations A and $\mathrm{B}$, was not included in the analysis.

During the wet period of the year (from November to April) the rainfall measurements at the Moira station were found to exhibit numerous small values in the range from $0.01-1 \mathrm{~mm} \mathrm{day}^{-1}$. Since the accuracy of the rain gauge at the Moira station is on the order of $1 \mathrm{~mm}^{-1 a y}{ }^{-1}$ (PPC, personal communication, 2012) and the Moira station is located in a forested area with significant vegetation, those values should be associated with dew and fog drip (occult precipitation) and were set to zero.

Tables 4 and 5 show annual rainfall depths and the fraction of wet days for the available historical rainfall records. One sees that (1) contrary to the original precipitation series at Moira the corrected ones exhibit lower wet-day fractions
Table 3. Number of missing values of daily rainfall measurements at station C (Moira).

\begin{tabular}{lcc}
\hline \multicolumn{2}{c}{ Period } & $\begin{array}{c}\text { No. of } \\
\text { values } \\
\text { start }\end{array}$ \\
\hline missing \\
\hline 1 Oct 1976 & 30 Sep 1977 & 5 \\
1 Oct 1983 & 30 Sep 1984 & 2 \\
1 Oct 1986 & 30 Sep 1987 & 152 \\
1 Oct 1987 & 30 Sep 1988 & 154 \\
1 Oct 1988 & 30 Sep 1989 & 157 \\
1 Oct 1992 & 30 Sep 1993 & 25 \\
1 Oct 1993 & 30 Sep 1994 & 30 \\
\hline
\end{tabular}

Table 4. Annual rainfall totals for the observed, corrected and calculated rainfall series.

\begin{tabular}{lrrrrr}
\hline \multicolumn{7}{c}{ Annual rainfall totals $\left(\mathrm{mm} \mathrm{yr}^{-1}\right)$} \\
\hline $\begin{array}{l}\text { Hydrological } \\
\text { year }\end{array}$ & Dam & HP & $\begin{array}{r}\text { Moira } \\
\text { original }\end{array}$ & $\begin{array}{r}\text { Moira } \\
\text { (corrected) }\end{array}$ & $\begin{array}{r}\text { Spatial } \\
\text { rainfall }\end{array}$ \\
\hline $74-75$ & 771.7 & 595.0 & - & - & - \\
$75-76$ & 762.5 & 609.9 & 1184.8 & 1174.6 & 1092.2 \\
$76-77$ & 646.4 & 710.7 & 1071.7 & 1062.1 & 979.0 \\
$77-78$ & 1163.5 & 1097.9 & 1667.5 & 1656.2 & 1557.7 \\
$78-79$ & 1036.7 & 969.2 & 1328.1 & 1314.4 & 1258.9 \\
$79-80$ & 1221.6 & 1096.0 & 1762.8 & 1746.5 & 1641.5 \\
$80-81$ & 1178.3 & 1029.7 & 1709.9 & 1691.2 & 1588.6 \\
$81-82$ & 1122.6 & 976.8 & 1579.0 & 1572.6 & 1482.6 \\
$82-83$ & 974.2 & 892.1 & 1237.4 & 1229.7 & 1178.6 \\
$83-84$ & 892.5 & 874.1 & 1307.7 & 1295.2 & 1214.7 \\
$84-85$ & 667.3 & 598.1 & 917.6 & 906.9 & 859.0 \\
$85-86$ & 937.9 & 865.2 & 1374.6 & 1361.0 & 1276.4 \\
$86-87$ & 830.5 & 755.6 & 1068.9 & 1060.5 & 1014.5 \\
$87-88$ & 764.3 & 671.1 & 987.2 & 969.8 & 928.7 \\
$88-89$ & 632.0 & 572.3 & 670.3 & 662.9 & 656.7 \\
$89-90$ & 504.7 & 496.3 & 718.3 & 704.2 & 664.3 \\
$90-91$ & 941.0 & 901.2 & 1105.5 & 1086.0 & 1057.0 \\
$91-92$ & 517.0 & 409.1 & 618.0 & 602.7 & 585.6 \\
$92-93$ & 547.7 & 532.5 & 919.6 & 911.3 & 838.6 \\
\hline
\end{tabular}

that are closer to those observed at different locations inside and outside the catchment (see Table 5) and that (2) the corresponding correction affects minimally the annual rainfall totals (see Table 4).

For the period common to all stations (i.e. 1 October 1975 to 30 September 1993), we used the original precipitation data at station B (dam) and the corrected ones at station $\mathrm{C}$ (Moira) to calculate spatial rainfall averages using the method of Thiessen polygons; see Tables 4 and 5. The weighting coefficients were found to be 0.2 for station B and 0.8 for station $\mathrm{C}$.

While station A is located outside the study area, its small distance from the boundaries of the basin $(2 \mathrm{~km})$ allows one to include it in the analysis as it was located on the basin divide; see also Sects. 3 and 4.2. Since rain gauge $A$ is not used for the calculation of the mean areal precipitation inside the 
Table 5. Fraction of wet days for the observed, corrected and calculated rainfall series.

\begin{tabular}{lccccc}
\hline \multicolumn{5}{c}{ Fraction of wet days } \\
\hline $\begin{array}{l}\text { Hydrological } \\
\text { year }\end{array}$ & HP & Dam & $\begin{array}{c}\text { Moira } \\
\text { original }\end{array}$ & $\begin{array}{c}\text { Moira } \\
\text { (corrected) }\end{array}$ & $\begin{array}{c}\text { Spatial } \\
\text { rainfall }\end{array}$ \\
\hline $74-75$ & 0.118 & 0.148 & - & - & - \\
$75-76$ & 0.200 & 0.205 & 0.342 & 0.258 & 0.288 \\
$76-77$ & 0.184 & 0.159 & 0.263 & 0.208 & 0.222 \\
$77-78$ & 0.260 & 0.230 & 0.395 & 0.301 & 0.312 \\
$78-79$ & 0.233 & 0.211 & 0.419 & 0.268 & 0.290 \\
$79-80$ & 0.263 & 0.255 & 0.468 & 0.299 & 0.326 \\
$80-81$ & 0.230 & 0.222 & 0.425 & 0.268 & 0.285 \\
$81-82$ & 0.225 & 0.219 & 0.381 & 0.279 & 0.290 \\
$82-83$ & 0.197 & 0.192 & 0.282 & 0.205 & 0.236 \\
$83-84$ & 0.230 & 0.222 & 0.405 & 0.266 & 0.285 \\
$84-85$ & 0.170 & 0.167 & 0.304 & 0.216 & 0.255 \\
$85-86$ & 0.214 & 0.214 & 0.340 & 0.266 & 0.290 \\
$86-87$ & 0.148 & 0.153 & 0.247 & 0.203 & 0.216 \\
$87-88$ & 0.173 & 0.173 & 0.255 & 0.184 & 0.236 \\
$88-89$ & 0.129 & 0.121 & 0.189 & 0.151 & 0.170 \\
$89-90$ & 0.090 & 0.079 & 0.203 & 0.137 & 0.167 \\
$90-91$ & 0.197 & 0.195 & 0.334 & 0.222 & 0.260 \\
$91-92$ & 0.063 & 0.058 & 0.255 & 0.162 & 0.189 \\
$92-93$ & 0.126 & 0.126 & 0.208 & 0.153 & 0.192 \\
\hline
\end{tabular}

catchment (see above), obtaining results also for this station allows one to compare the estimated mean areal precipitation from stations B and C (using the method of Thiessen polygons), to rainfall products derived independently from station A using the suggested methodology.

\subsection{River discharge time series}

Daily discharge measurements at the outlet of the hydroelectric plant (point A in Fig. 2) are available from 1 October 1974 onward. These measurements correspond to the mean daily river flow at the outlet of the catchment (dam), as the river water from the reservoir is led to the hydroelectric plant through a pipeline. In the case of very high river discharges, a portion of the river water entering the reservoir is not used for energy production and flows downstream through the spillway of the dam. This portion of the river discharge is measured at the spillway. The mean daily discharge is obtained as the sum of the daily water volume supplied to the hydroelectric plant and the daily water volume flowing out of the reservoir through the spillway of the dam.

The historical discharge series have been corrected to eliminate sudden and intense drops of the measured runoff caused by abrupt operations on the energy production unit. In addition, daily discharge measurements below $0.25 \mathrm{~m}^{3} \mathrm{~s}^{-1}$ were found to exhibit irregular fluctuations during summer months, in the absence of rain. Those fluctuations relate to the observation accuracy of the water level in the discharge channel of the hydroelectric plant (PPC, personal communication, 2012) and were smoothed out by assigning a minimum discharge value $=0.25 \mathrm{~m}^{3} \mathrm{~s}^{-1}$. (Note that the Glafkos river is a perennial stream with non-zero base flow during all years on record.) Table 6 shows annual discharges, per unit area of the basin, for the historical years on record, using the original and corrected discharge series. One sees that the applied corrections affect minimally the annual water volumes.

\subsection{Temperature time series}

Daily mean temperatures are available from the stations of the Hellenic National Meteorological Service (HNMS) in Patras (point $\mathrm{T}$ in Fig. 2) and Araxos (approximately $30 \mathrm{~km}$ west of the city of Patras; not included in the map). The Patras station is located at an altitude of $1 \mathrm{~m}$ (a.m.s.l.) with available data for the period 1 October 1982-30 September 2000, whereas Araxos station is located at an altitude of $15 \mathrm{~m}$ (a.m.s.1.) and has been operating since 1 October 1974. When calculating the actual evapotranspiration in the basin (Sect. 5) for the period 1 October 1974-30 September 1982 (where no measurements are available at the Patras station), we use mean annual temperatures from Araxos corrected to account for the difference between the mean elevation of the catchment (1060 m a.m.s.l.; see Table 2) and the altitude of the station, using a pseudo-adiabatic lapse rate equal to $0.65^{\circ} \mathrm{C} / 100 \mathrm{~m}$ (see Table 7). For the period 1 October 1982 30 September 1993 we use the daily mean temperatures recorded at the Patras station (the closest station to the basin), also corrected to account for the difference between the mean elevation of the catchment and the altitude of the station. As shown by Ziogas (2006), the daily mean temperatures measured at Patras and Araxos are highly correlated (correlation coefficient $R=0.96$ ) and one can combine those records to cover the whole period of the analysis.

\section{A statistical approach to identify and resolve incompatibilities between daily rainfall measurements and river discharges}

\subsection{Checking rainfall occurrence using a theoretically based statistical model}

Define $Q(t)$ to be the river discharge at the outlet of a basin on day $t$, and denote by $S(t)$ the subsurface storage on the same day. A simple theoretical model to approximate river discharges on dry days is that of a linear reservoir with zero inflow (see e.g. Chow, 1964; Lettenmaier and Wood, 1993):

$$
\left.\begin{array}{l}
Q(t)=\alpha S(t) \\
\mathrm{d} S(t)=-Q(t) \mathrm{d} t
\end{array}\right\} \Rightarrow Q(t)=Q(t-\mathrm{d} t) e^{-\alpha \mathrm{d} t},
$$

where $\alpha \geq 0$ is a time constant. For $\mathrm{d} t=1$ day, it follows from Eq. (2) that the ratio

$\omega(t)=\frac{Q(t)-Q(t-1)}{Q(t-1)}=e^{-\alpha}-1=$ const. $<0$. 

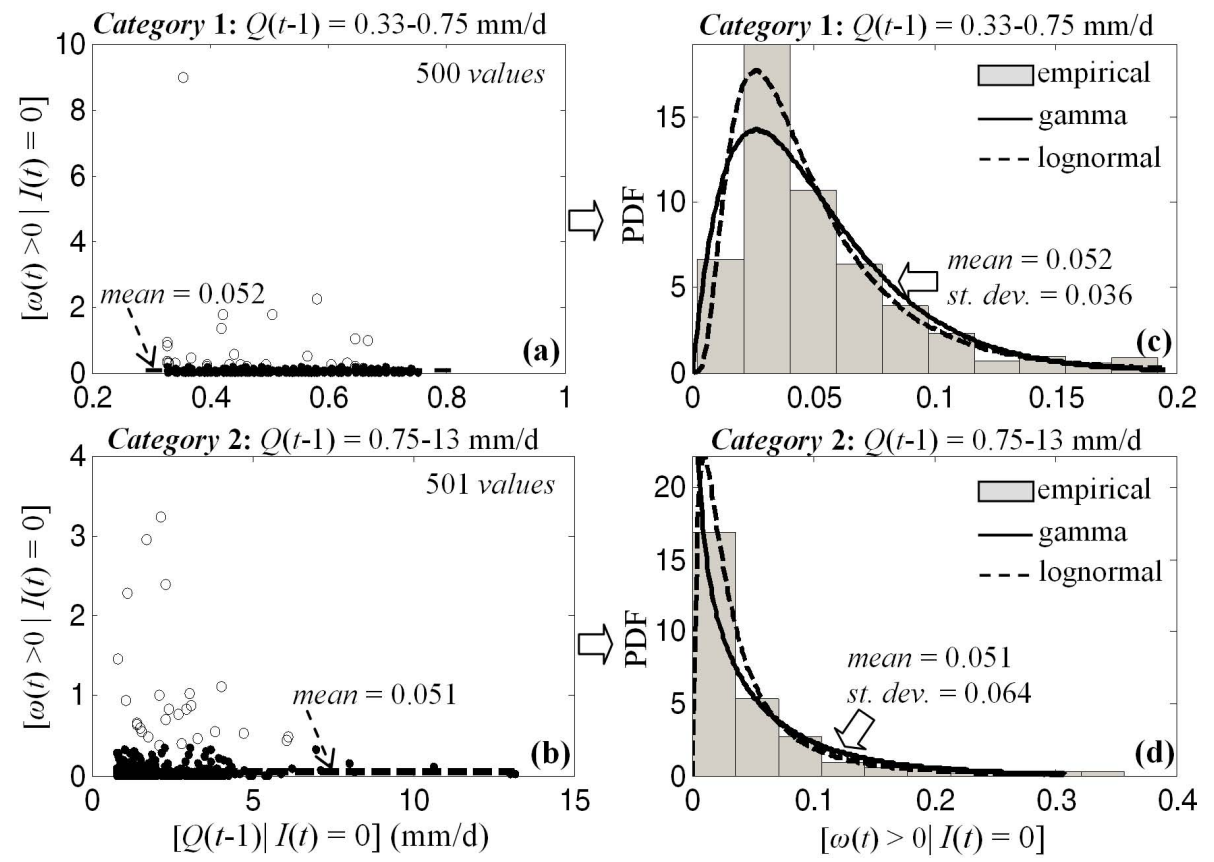

Fig. 3. (a, b) Scatter plots of the empirical ratios $[\omega(t)>0 \mid I(t)=0]$, calculated using daily discharges and rainfall data from the hydroelectric plant (HP; point A in Fig. 2) for the period 1 October 1974-30 September 1993 (i.e. 19 yr, 1001 points) and split into 2 equally populated categories with respect to the previous-day river discharge $Q(t-1)$. Empty circles indicate values of $\omega$ for which the null hypothesis of no rain over the catchment is rejected at the $5 \%$ significance level; see main text. (c, d) Empirical histograms of the ratios (dots) in (a) and (b) fitted by gamma (solid lines) and lognormal (dashed lines) distribution models.

Deviations from the model in Eq. (2) may cause the time constant $\alpha$ and consequently the ratio $\omega$ to vary slowly with the previous-day discharge $Q(t-1)$.

Strictly speaking, in the absence of rain, positive values of $\omega$ are very likely not feasible, especially in Mediterranean basins. Hence, while small positive values (say on the order of 0.2-0.5) may be justified by snowmelt, variations of base flow and light rainfall occurrence at some ungauged part of the catchment, larger values of $\omega$ should be associated with measurement errors or heavy rainfall at some ungauged part of the catchment.

Figures 3-5 show scatter-plots and empirical histograms of $[\omega(t)>0 \mid I(t)=0]$ using daily river discharges and rainfall depths measured at points A (HP) and B (dam) for the period 1 October 1974-30 September 1993 (19yr) and C (Moira) for the period 1 October 1975-30 September 1993 (18 yr). The analysis has been conducted by (1) calculating the ratio $\omega(t)$ on days that appear as dry in the historical record of point rainfall measurements and (2) classifying the positive values of $\omega$ into $n=2$ equally populated categories with respect to the previous-day river discharge $Q(t-1)$. Classification is done in order to study how the statistics of $\omega$ depend on $Q(t-1)$; see below. The solid and dashed lines on the right panels of Figs. 3-5 correspond to gamma and lognormal distribution models, respectively, fitted directly to the empirical ratios using the method of moments. The fitting procedure is suited to account for and remove irregularly high values of $\omega$, as follows.

1. For each category of previous-day river discharges, $Q(t-1)$, one removes a single value of $\omega$ and fits the corresponding theoretical distribution model to the remainder values.

2. One checks whether the removed value can be classified as an outlier at a certain level of significance $\beta$ (e.g. $\beta=5 \%$ )

3. One repeats steps 1 and 2 for all values of $\omega$ in the category.

4. One fits the corresponding theoretical distribution model to those values of $\omega$ identified as non-outliers.

One sees that, independent of the category of the previousday discharge $Q(t-1)$, both gamma and lognormal distribution models fit equally well the data. In what follows, we choose to model $\omega$ using a lognormal distribution with parameters that depend on $Q(t-1)$.

As noted above, irregularly large values of $\omega$ should be associated with measurement errors or heavy rainfall at some ungauged part of the catchment. That said, one can formulate a simple statistical test using the lognormal (or gamma) distribution models in Figs. 3-5 to identify incompatibilities between days indicated as dry in the historical record of point 
Table 6. Annual discharges, per unit area of the basin, for the original and corrected runoff series for the period 1 October 1974 to 30 September 2010.

\begin{tabular}{lrrccc}
\hline \multicolumn{5}{c}{ Annual discharge $\left(\mathrm{mm} \mathrm{yr}^{-1}\right)$} \\
Hydrological & Measured & Corrected & $\begin{array}{c}\text { Hydrological } \\
\text { year }\end{array}$ & Measured & Corrected \\
\hline $74-75$ & 533.5 & 536.3 & $92-93$ & 250.6 & 251.1 \\
$75-76$ & 685.6 & 686.0 & $93-94$ & 438.5 & 439.8 \\
$76-77$ & 674.5 & 678.2 & $94-95$ & 486.9 & 491.4 \\
$77-78$ & 1072.9 & 1093.5 & $95-96$ & 797.8 & 798.3 \\
$78-79$ & 1084.9 & 1086.9 & $96-97$ & 785.8 & 788.8 \\
$79-80$ & 1346.1 & 1346.5 & $97-98$ & 579.1 & 582.4 \\
$80-81$ & 881.1 & 892.9 & $98-99$ & 801.7 & 804.5 \\
$81-82$ & 1185.6 & 1191.0 & $99-00$ & 622.2 & 625.2 \\
$82-83$ & 691.1 & 691.2 & $00-01$ & 516.2 & 517.0 \\
$83-84$ & 786.0 & 786.2 & $01-02$ & 581.4 & 582.0 \\
$84-85$ & 518.1 & 519.3 & $02-03$ & 799.8 & 870.1 \\
$85-86$ & 909.4 & 916.9 & $03-04$ & 495.7 & 496.2 \\
$86-87$ & 691.7 & 692.5 & $04-05$ & 527.7 & 529.9 \\
$87-88$ & 570.8 & 571.1 & $05-06$ & 722.1 & 722.2 \\
$88-89$ & 282.8 & 296.7 & $06-07$ & 285.8 & 293.8 \\
$89-90$ & 216.9 & 220.6 & $07-08$ & 313.5 & 324.4 \\
$90-91$ & 628.4 & 630.1 & $08-09$ & 652.7 & 659.5 \\
$91-92$ & 183.6 & 188.7 & $09-10$ & 674.3 & 675.8 \\
\hline
\end{tabular}
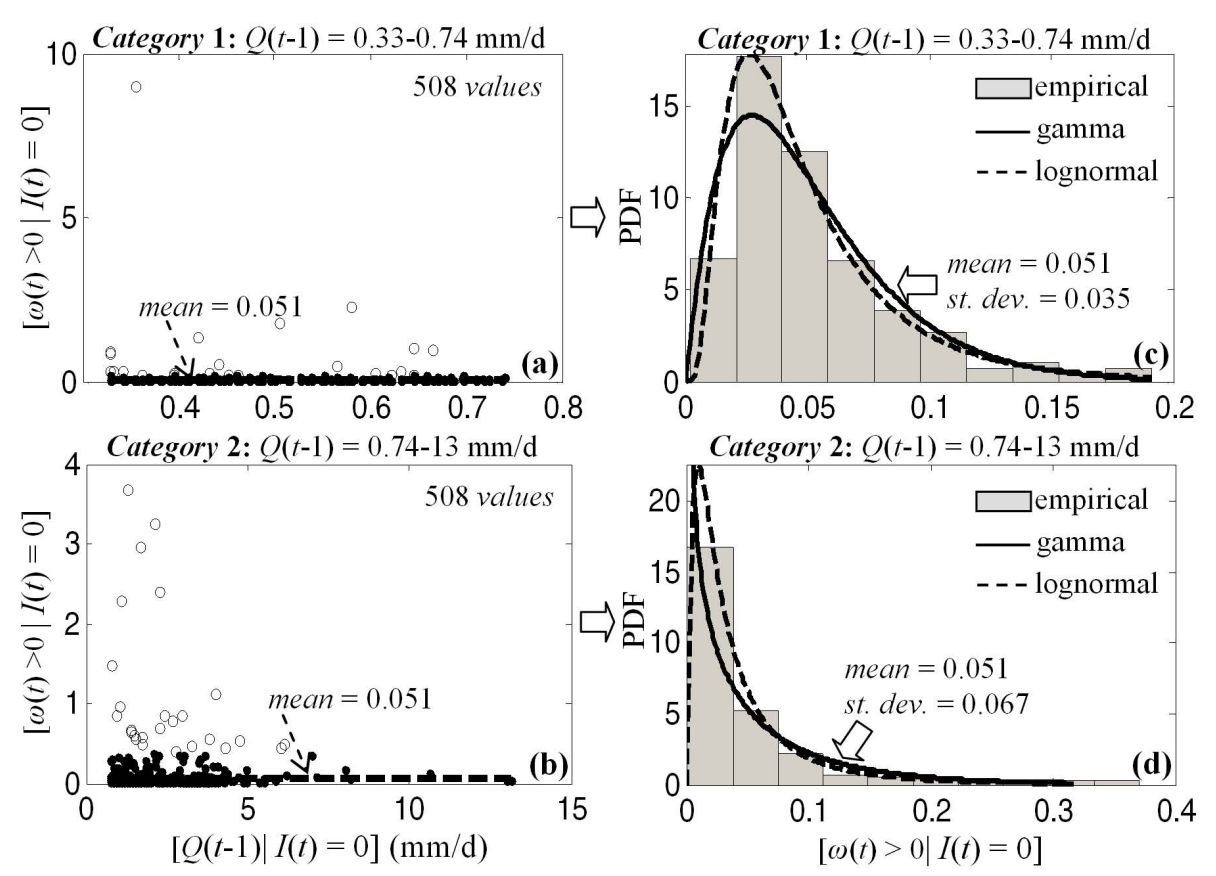

Fig. 4. Same as Fig. 3 but using daily rainfall intensities from the location of the dam (point B in Fig. 2) for the period 1 October 197430 September 1993 (i.e. $19 \mathrm{yr}, 1016$ points).

rainfall measurements and changes of the river discharge at the outlet of the basin. The left panels of Figs. 3-5 show scatter-plots of $\omega$ for different categories of river discharges and rainfall data sets. The empty circles indicate (outlier) values of $\omega$ for which the null hypothesis of no rain over the catchment is rejected at the $5 \%$ significance level.

An interesting observation is that, independent of the data set used, the values of $\omega$ (dots) satisfying the null hypothesis of no rain over the catchment have a constant mean $(\approx 0.05$; 


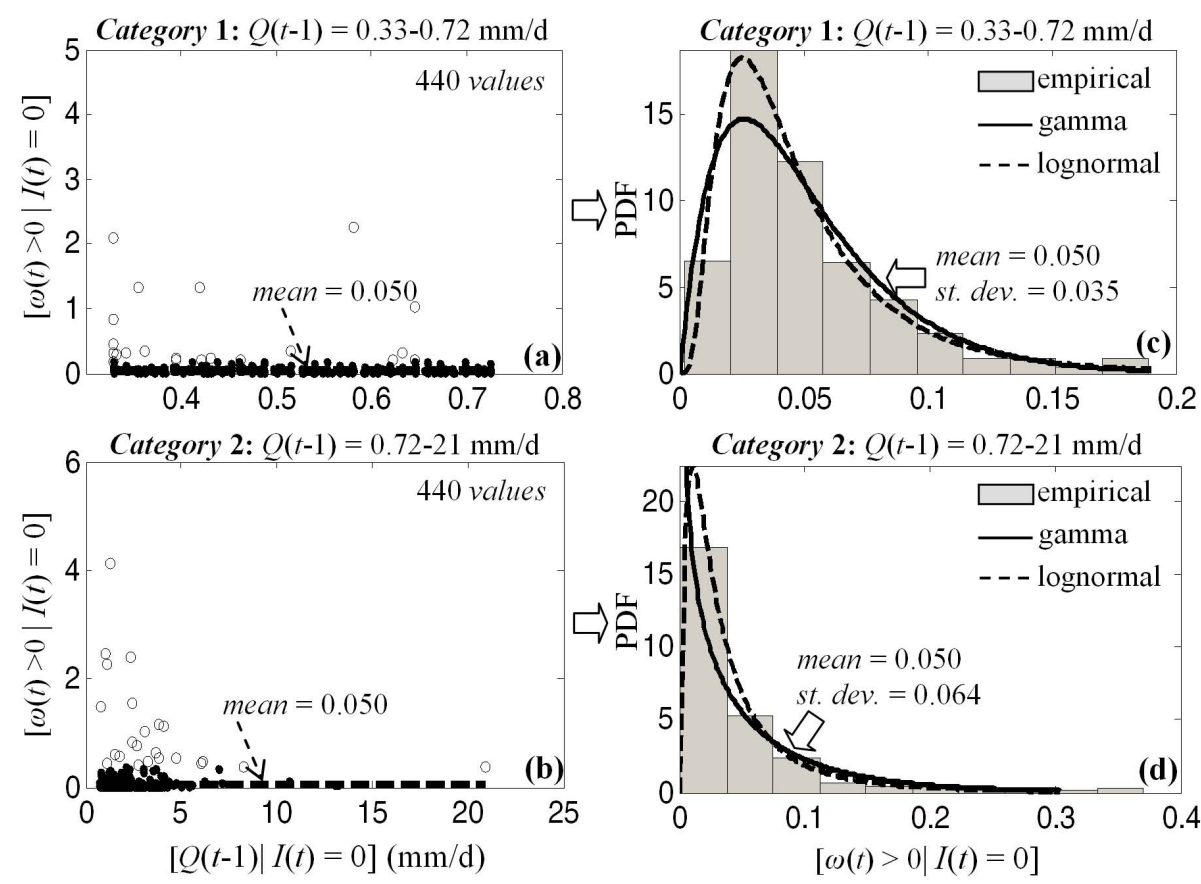

Fig. 5. Same as Fig. 4 but using daily rainfall intensities from the location of Moira (point C in Fig. 2) for the period 1 October $1975-$ 30 September 1993 (i.e. 18 yr, 880 points).

Table 7. Mean annual temperatures at the Glafkos catchment (mean elevation: 1060 ma.m.s.l.) for the period 1 October 1974 to 30 September 1993.

\begin{tabular}{lr}
\hline $\begin{array}{l}\text { Hydrological } \\
\text { year }\end{array}$ & $\begin{array}{r}\text { Mean } \\
\text { annual } \\
\text { temperature } \\
\left({ }^{\circ} \mathrm{C}\right)\end{array}$ \\
\hline $74-75$ & 9.83 \\
$75-76$ & 9.73 \\
$76-77$ & 10.60 \\
$77-78$ & 9.95 \\
$78-79$ & 10.43 \\
$79-80$ & 9.53 \\
$80-81$ & 9.98 \\
$81-82$ & 9.86 \\
$82-83$ & 10.33 \\
$83-84$ & 10.10 \\
$84-85$ & 10.93 \\
$85-86$ & 11.04 \\
$86-87$ & 10.51 \\
$87-88$ & 11.37 \\
$88-89$ & 10.63 \\
$89-90$ & 11.01 \\
$90-91$ & 9.83 \\
$91-92$ & 9.35 \\
$92-93$ & 10.69 \\
\hline
\end{tabular}

see Figs. 3-5) and a variance that increases with increasing $Q(t-1)$. The latter increase is physically justified since larger values of $Q(t-1)$ indicate intense discharge conditions that can more easily produce extreme runoffs. An additional observation is that, independent of the category of previous-day discharge $Q(t-1)$, the statistics of the values of $\omega$ that satisfy the null hypothesis do not depend on the rainfall data set. This highlights the robustness of the statistical method in identifying and eliminating incompatibilities between daily rainfall occurrences and changes in the river runoff, while maintaining those values of $\omega$ that share similar statistics. In the next section we focus on wet days and model daily rainfall intensities using a lognormal distribution with parameters that depend on the same- and previous-day discharge conditions at the outlet of the catchment.

\subsection{Statistical model for daily rainfall intensities conditioned on river discharges}

Our interest is in developing a statistical tool to (a) assign synthetic rainfall intensity values to days that appear as dry in the historical record of point rainfall measurements, but the flow conditions at the outlet of the catchment classify them as wet at a certain confidence level $\gamma$ (e.g. $\gamma=1-\beta=95 \%$; see empty circles in Figs. 3-5) and (b) check and correct inconsistencies in rainfall amounts on wet days conditional on the flow conditions at the outlet of the catchment. 

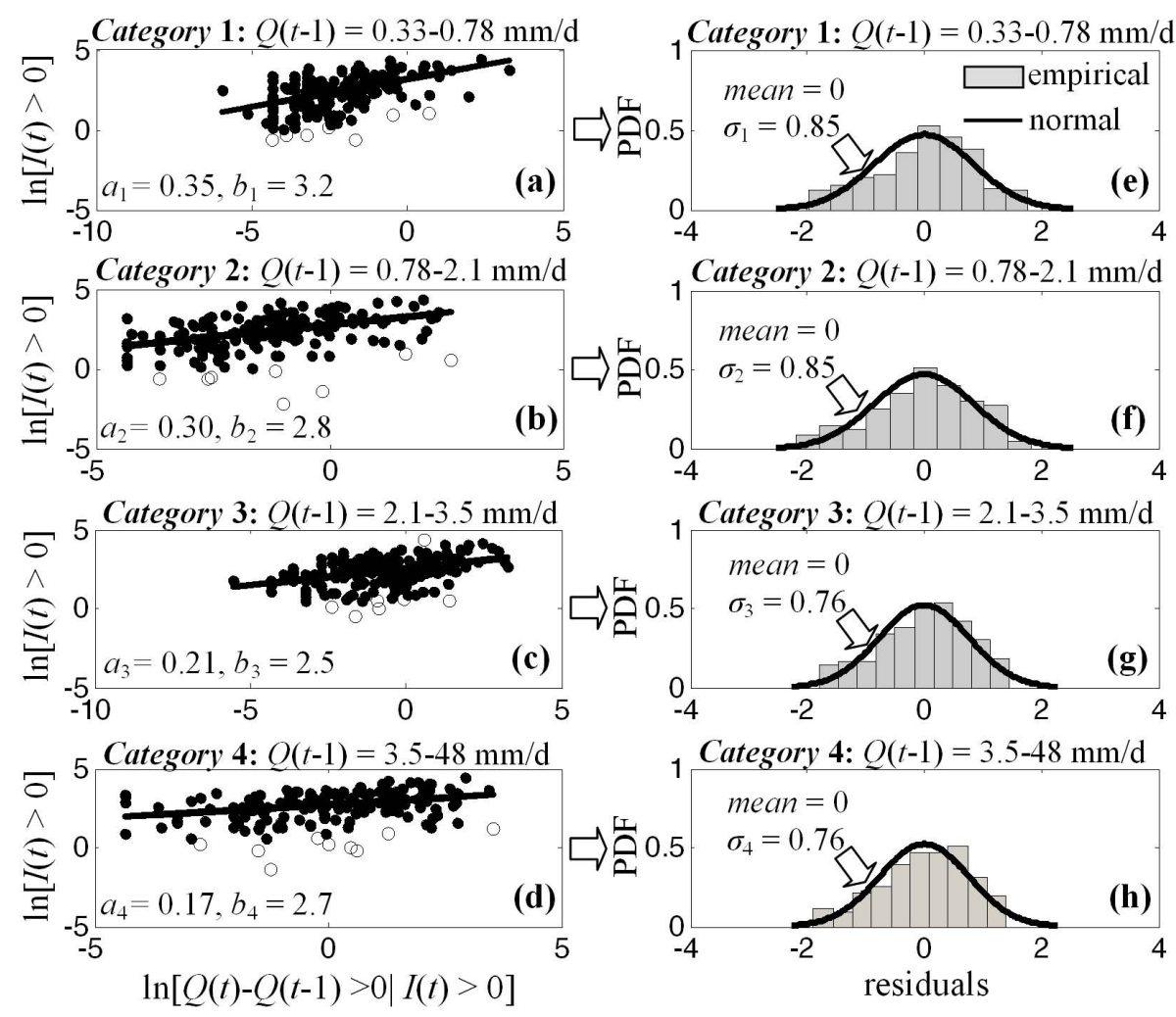

Fig. 6. (a-d) Plots of logarithmically transformed daily rainfall intensities on wet days, $\ln [I(t)>0]$, as a function of the observed change of the river discharge $\ln [Q(t)-Q(t-1)>0]$ for 4 (four) equally populated categories of the previous-day river discharge $Q(t-1)$. The analysis has been conducted using daily discharges and rainfall data from the location of the hydroelectric plant (HP; point A in Fig. 2) for the period 1 October 1974-30 September 1993 (i.e. $19 \mathrm{yr}, 656$ points). Estimates of the parameters $a_{j}$ and $b_{j}(j=1, \ldots, 4)$ in Eq. (4) have been obtained by least-squares fitting of the empirical values. Empty circles correspond to outliers of the log-log linear regression at $5 \%$ significance level. (e-h) Empirical histograms of the residuals of the log-log linear regression in (a-d) fitted by a normal distribution model with zero mean and variance $\left(\sigma_{j}\right)^{2}=\operatorname{Var}\left[V_{j}\right]$; see Eq. (4).

A way to proceed in this direction is to develop relationships that describe how the statistics of daily rainfall intensities vary with indicator variables representative of the flow conditions at the outlet of the basin. For the same data sets used in Figs. 3-5, Figs. 6-8 show plots of the logarithmically transformed daily rainfall intensities, $\ln [I(t)>0]$, on wet days $t$ as a function of the observed positive change of the river discharge $[Q(t)-Q(t-1)>0]$ for different categories of the previous-day discharge $Q(t-1)$. Dependence of the statistics of $[I(t)>0]$ on $Q(t-1)$ and $[Q(t)-Q(t-1)>0]$ is physically justified, since (a) larger values of $Q(t-1)$ indicate intense discharge conditions that more easily produce extreme runoffs and, consequently, larger values of the difference $Q(t)-Q(t-1)$, and since (b) larger values of the difference $Q(t)-Q(t-1)$ are associated with more-intense rainfall events.

The solid lines on the left panels of Figs. 6-8 are best fits of Eq. (4) (see below) to the empirical data using the method of least squares,

$$
\begin{aligned}
\ln [I(t) & >0 \mid Q(t)-Q(t-1)>0] \\
& =a_{j} \ln [Q(t)-Q(t-1)>0]+b_{j}+V_{j}, \\
& j=1,2, \ldots, m .
\end{aligned}
$$

$a_{j}$ and $b_{j}$ in Eq. (4) are parameters that depend on the category $j$ of the previous-day discharge $Q(t-1)$, and $V_{j}$ is a zero-mean random error term that is stochastically independent from the variable $[Q(t)-Q(t-1)]$. Calculation of the parameters $a_{j}$ and $b_{j}$ proceeds as follows.

1. One identifies the wet days (i.e. $I(t)>0)$ in the historical record for which $Q(t)-Q(t-1)>0$. For those days, the measured rainfall intensities $I(t)$ and the observed changes of the river runoff $Q(t)-Q(t-1)$ are ranked based on the previous-day river flow $Q(t-1)$ and split into $m=4$ equally populated categories.

2. The coefficients $a_{j}$ and $b_{j}$, as well as the residuals of the regression $v_{j}, k, k=1,2, \ldots$, are calculated separately for each category $j$ using the method of least squares. 

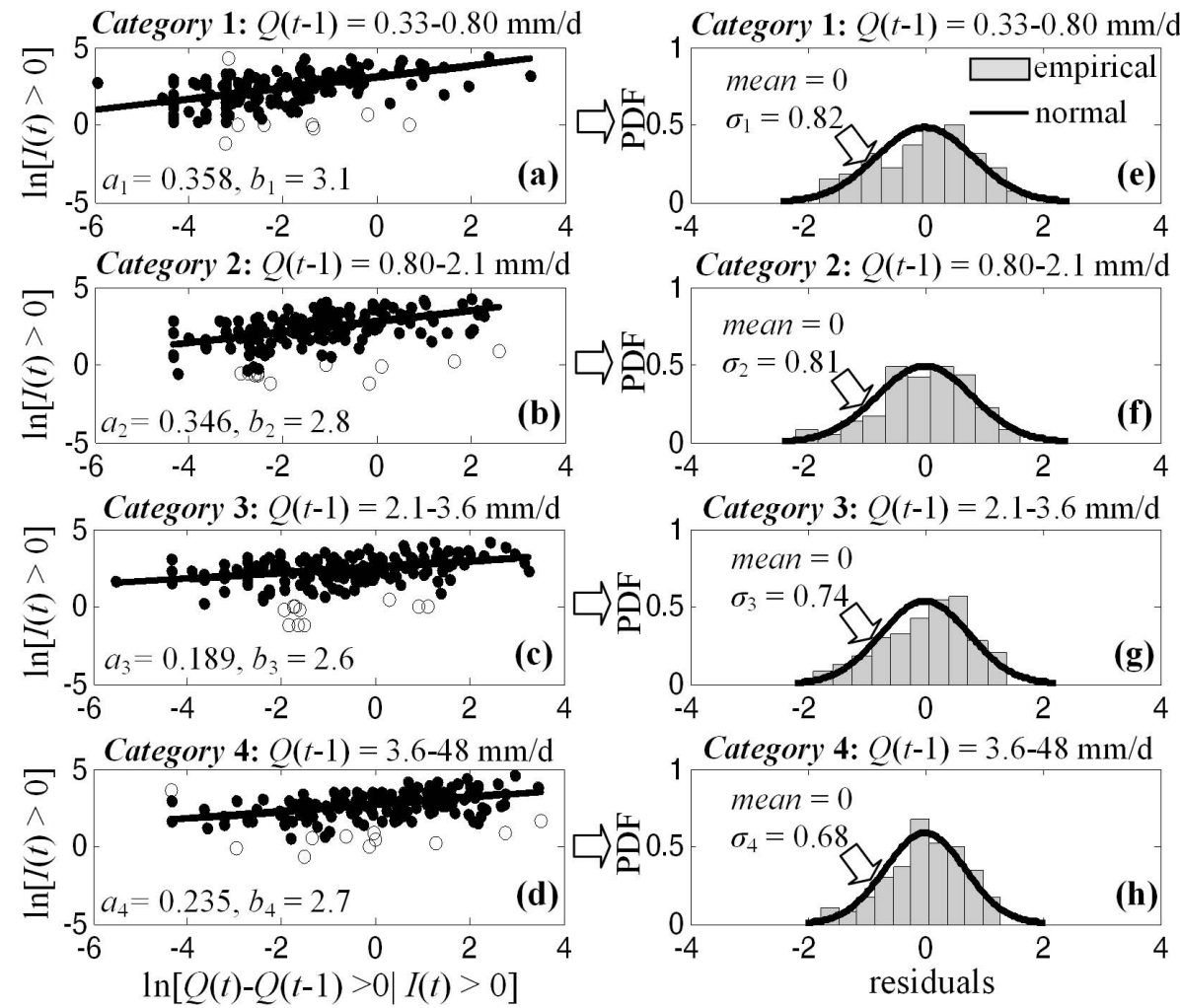

Fig. 7. Same as Fig. 6 but using daily rainfall intensities from the location of the dam (point B in Fig. 2) for the period 1 October $1974-$ 30 September 1993 (i.e. $19 \mathrm{yr}, 641$ points).

3. To put residuals at a comparable scale, one divides them by an estimate of their standard deviation (see Chatterjee and Hadi, 1986, Eq. 13) that is independent of their value. As shown on the right panels of Figs. 6-8, independent of the category $j$ of the previous-day river discharge $Q(t-1)$, the residuals of the $\log -\log$ linear regression are well approximated by a normal distribution with zero mean and variance $\sigma_{j}^{2}$ that depends on the category $j$. Hence, the resulting samples of the standardized residuals should be well approximated by a Student $t$ distribution with $N_{j}-p-1$ degrees of freedom (df), where $N_{j}$ is the sample size of category $j$ and $p=2$ is the number of parameters of the log-linear regression; see e.g. Belsley et al. (1980), Velleman and Welsch (1981), Atkinson (1981) and Chatterjee and Hadi (1986).

4. For a certain level of significance $\beta$ (e.g., $5 \%$ ), one uses the standardized residuals from step 3 and the Student $t$ theoretical distribution model to identify outliers of the initial regression (see empty circles on the left panels of Figs. 6-8), remove them, and then obtain a new set of coefficients $a_{j}$ and $b_{j}$.

Figure 9 shows how the empirical estimates of the parameters $a_{j}$ and $b_{j}$ in Eq. (4) and the error standard deviation $\sigma_{j}$ vary with the previous-day discharge $Q(t-1)$. The solid lines are least-squares fits to the empirical values. One sees that both $a$ and $b$ decrease $\log -\log$ linearly with increasing $Q(t-1)$. This is physically expected since larger values of $Q(t-1)$ correspond to more-intense discharge conditions, where large changes of the river discharge between two sequential days $Q(t)-Q(t-1)$ can also be caused by less intense rainfall events.

Two additional observations one makes are that, independent of the rainfall data set, the empirical distribution of the residuals of the regression in Eq. (4) is close to normal with variance that does not depend on the previous-day discharge $Q(t-1)$. The first observation is in accordance with the findings of many studies suggesting the use of a lognormal distribution model for rainfall intensities; see e.g. Kedem et al. (1990a,b, 1997), Shimizu (1993), Cheng and Qi (2002), Cho et al. (2004), Veneziano and Langousis (2005a,b), Shoji and Kitaura (2006), Veneziano et al. (2006, 2007), Suhaila and Jemain (2007), Langousis and Veneziano (2007), and Langousis et al. (2009). The second observation is physically justified since the variability of rainfall should not depend on the previous-day flow conditions.

Based on the above findings, in what follows we model daily rainfall intensities, conditional on river discharge conditions, using a lognormal distribution model with parameters 

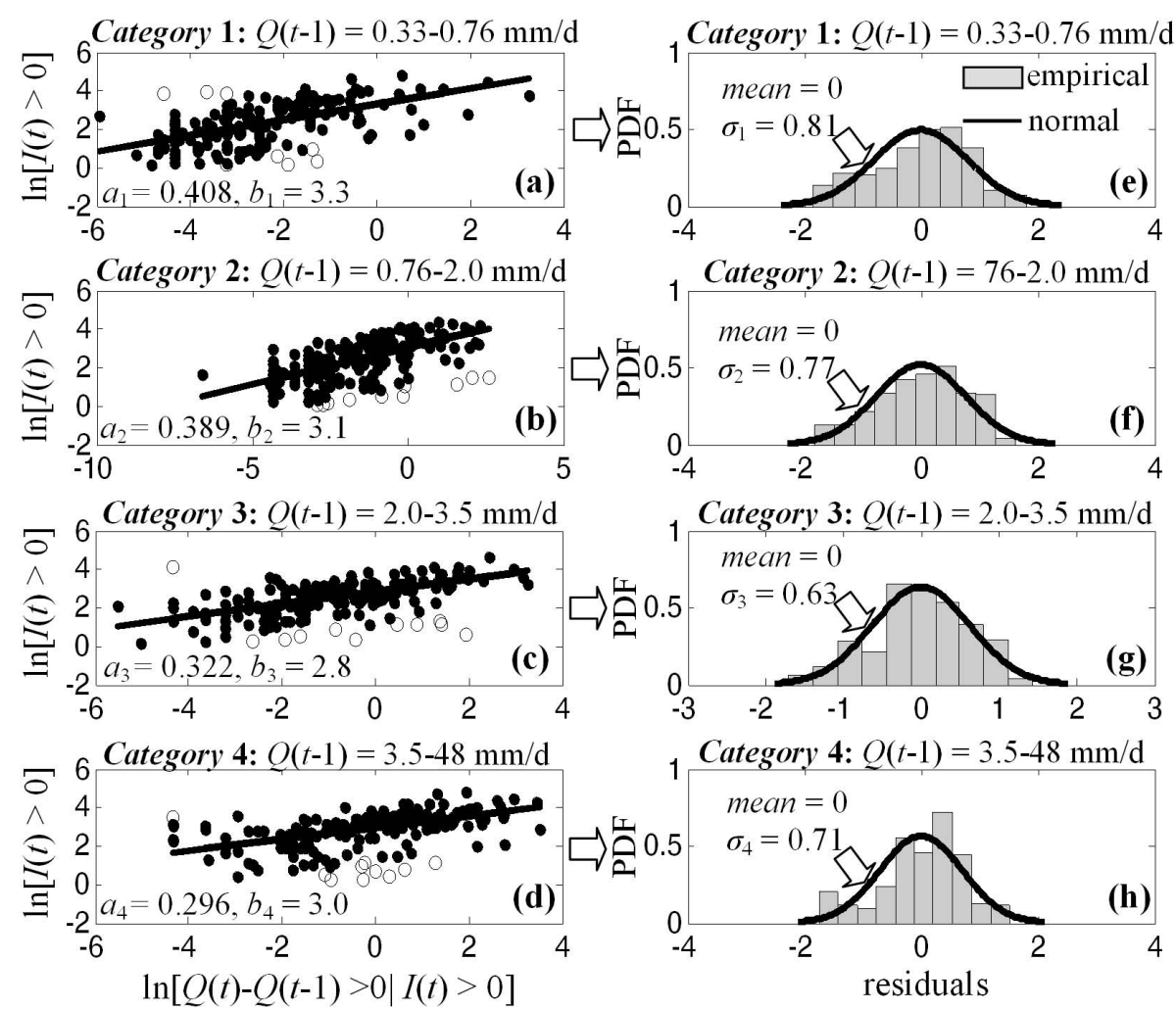

Fig. 8. Same as Fig. 7 but using daily rainfall intensities from Moira station (point C in Fig. 2) for the period 1 October 1975-30 September 1993 (i.e. $18 \mathrm{yr}, 695$ points).

$$
\begin{aligned}
& \mu_{\ln I}=E[\ln \{I(t)>0 \mid Q(t)-Q(t-1)>0, Q(t-1)\}] \\
& =a_{Q(t-1)} \ln [Q(t)-Q(t-1)>0]+b_{Q(t-1)} \\
& \begin{aligned}
\left(\sigma_{\ln I}\right)^{2} & =\operatorname{Var}[\ln \{I(t)>0 \mid Q(t)-Q(t-1)>0, Q(t-1)\}] \\
& =c^{2}=\text { const. }
\end{aligned}
\end{aligned}
$$

where $\mu_{\ln I}$ and $\left(\sigma_{\ln I}\right)^{2}$ are the mean and variance of the associated normal distribution, $a_{Q(t-1)}$ and $b_{Q(t-1)}$ can be calculated from the equations in Fig. 9 based on the previousday discharge $Q(t-1)$, and $c$ is a constant independent of $Q(t-1)$. Equation (5) is used to assign synthetic rainfall intensity values to (1) days identified with inconsistencies between point rainfall measurements and flow conditions at the outlet of the catchment (see empty circles in Figs. 3-8) and to (2) additional wet days when adjusting point rainfall measurements to better resemble the fraction of wet intervals in spatial rainfall averages; see next section.

\section{Using concepts from multifractal theory to relate the fraction of wet intervals in point rainfall to that in spatial rainfall averages}

Define $\bar{I}(t)$ to be the spatially averaged daily rainfall depth over a catchment on day $t$, and denote by $I(t)$ the daily rainfall depth at a certain location $j$ inside the basin on the same day. From total probability theorem one has

$$
\begin{aligned}
P[\bar{I}(t)>0] & =1-\bar{P}_{0}=P[\bar{I}(t)>0 \mid I(t)>0]\left(1-P_{0}\right) \\
& +P[\bar{I}(t)>0 \mid I(t)=0] P_{0},
\end{aligned}
$$

where $\bar{P}_{0}=P[\bar{I}(t)=0]$ and $P_{0}=P[I(t)=0]$, and from conditional probability theorem one has

$$
P[\bar{I}(t)>0 \mid I(t)=0]=\frac{\left(1-\bar{P}_{0}\right) P[I(t)=0 \mid \bar{I}(t)>0]}{P_{0}} .
$$

By combining Eqs. (6) and (7) one obtains

$\bar{P}_{0}=1-\frac{\delta\left(1-P_{0}\right)}{1-P[I(t)=0 \mid \bar{I}(t)>0]}$,

where $\delta=P[\bar{I}(t)>0 \mid I(t)>0]$.

It follows from the definition of spatial rainfall averages that when $j$ is located inside the catchment or at the basin divide, $\delta=1$. Thus,

$\bar{P}_{0}=1-\frac{\left(1-P_{0}\right)}{1-P[I(t)=0 \mid \bar{I}(t)>0]}$.

In the next two sub-sections we use scaling arguments from multifractal theory and a simple theoretical model to relate 

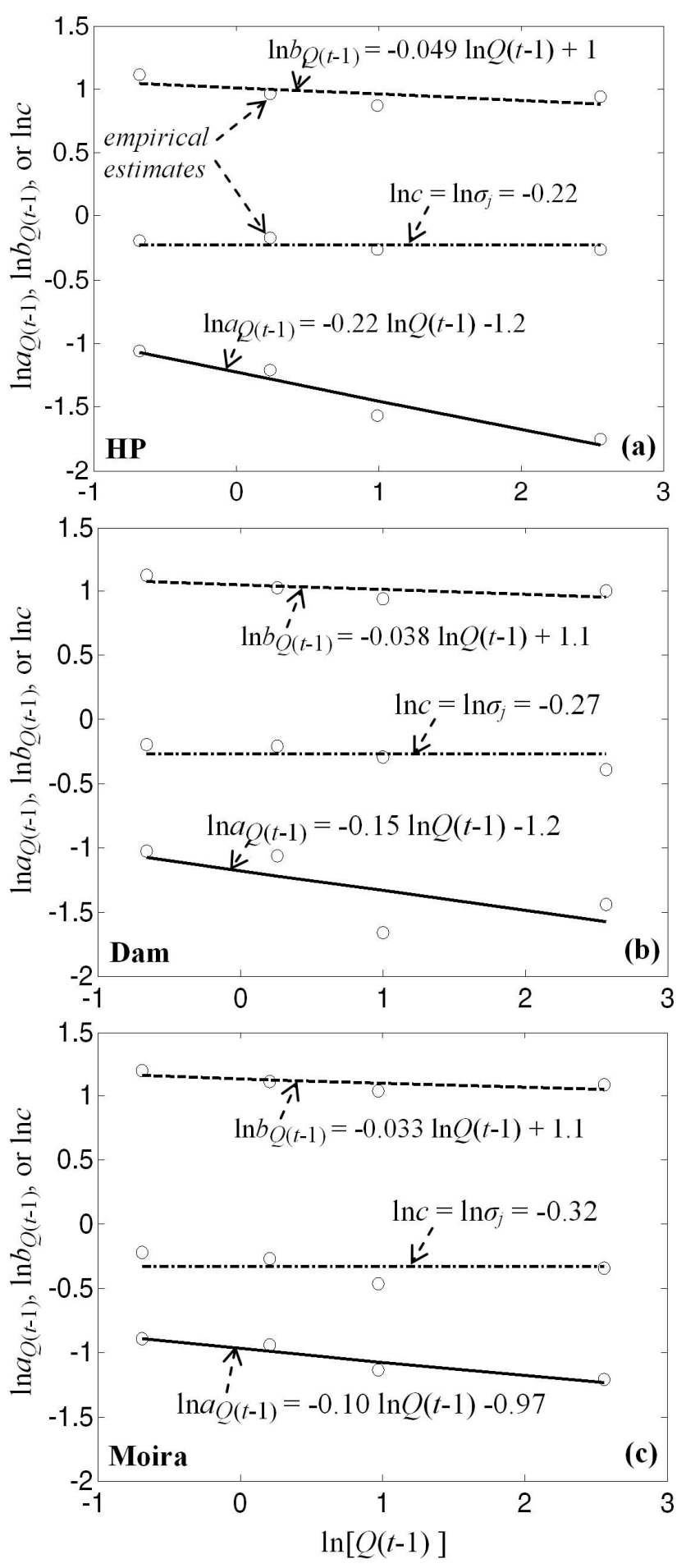

Fig. 9. Plots of the parameters $a_{j}$ and $b_{j}(j=1, \ldots, 4)$ in Eq. (4), and the error standard deviation $\sigma_{j}=\operatorname{Var}\left[V_{j}\right]^{0.5}$ as functions of the previous-day river discharge $Q(t-1)$, for the rainfall data sets used in Figs. 6-8. Lines correspond to least-squares (LS) fits to the empirical values.
Table 8. Categories of precipitation areas and their characteristics; adapted from Langousis (2005).

\begin{tabular}{lllll}
\hline Type & Area, $A_{\max }$ & $\begin{array}{l}\text { Linear } \\
\text { dimension, } \\
L_{\max }\end{array}$ & $\begin{array}{l}\text { Lifetime, } \\
d_{\mathrm{L}}\end{array}$ & $\begin{array}{l}\text { Advection } \\
\text { velocity, } \\
v_{\mathrm{ad}}\end{array}$ \\
\cline { 1 - 4 } small areas & $\sim 10 \mathrm{~km}^{2}$ & $3 \mathrm{~km}$ & $<30 \mathrm{~min}$ & \\
\cline { 1 - 4 } $\begin{array}{l}\text { small } \\
\text { mesoscale } \\
\text { areas }\end{array}$ & $100-400 \mathrm{~km}^{2}$ & $10-20 \mathrm{~km}$ & $\sim 1 \mathrm{~h}$ & $30-50 \mathrm{~km} \mathrm{~h}^{-1}$ \\
$\begin{array}{lllll}\text { large } \\
\text { mesoscale } \\
\text { areas }\end{array}$ & $10^{3}-10^{4} \mathrm{~km}^{2}$ & $30-100 \mathrm{~km}$ & $\begin{array}{l}\text { several } \\
\text { hours }\end{array}$ & \\
\cline { 1 - 2 } $\begin{array}{l}\text { synoptic } \\
\text { scale areas }\end{array}$ & $>10^{4} \mathrm{~km}^{2}$ & $>100 \mathrm{~km}$ & $\geq 10 \mathrm{~km} \mathrm{~h}^{-1}$ & \\
\hline
\end{tabular}

the probability $P[I(t)=0 \mid \bar{I}(t)>0]$ in Eq. (9) (i.e. the probability that it does not rain at location $j$ given that it rains inside the basin) to the shape and size of the catchment and the characteristics of storms.

\subsection{Borrowing concepts from multifractal theory to approximate Eq. (9)}

Rainfall-generating features evolve in time and advect in space. Hence, rain gauge rainfall measurements are representative estimates of spatial rainfall averages over an indicative area $A_{0}$, which depends on the characteristics (size, lifetime, advection velocity vector, etc.) of rainfall-generating features. Suppose now that spatial rainfall is homogeneously multifractal below some maximum area $A_{\max } \propto\left(L_{\max }\right)^{2}$, where $L_{\max }$ is the linear spatial dimension of the rainfallgenerating features; see below. In this case (see e.g. Schertzer and Lovejoy, 1987; Gupta and Waymire, 1993; Veneziano, 1999; Veneziano and Langousis, 2010),

$I(t) \stackrel{\mathrm{d}}{=} Y_{\mathrm{r}} \bar{I}(t)$,

where $\stackrel{\mathrm{d}}{=}$ denotes equality in all finite dimensional distributions, $Y_{\mathrm{r}}$ is a unit mean random variable independent of $\bar{I}(t)$ with parameters that depend on the resolution $r=A / A_{0}<A_{\max } / A_{0}$, and $A$ is the area of the catchment. Estimates of $A_{\max }$ and $L_{\max }$ are summarized in Table 8; see e.g. Austin and House (1972), Orlanski (1975), Veneziano and Langousis (2005a), and the review in Langousis (2005). For subtropical regions where rainfall is mainly dominated by stratiform formations, an average value of $L_{\max }$ is on the order of $50-100 \mathrm{~km}$ or more.

For spatial rainfall fields, a commonly used assumption to model the alternation of wet and dry regions is the use of a beta-lognormal distribution model for $Y_{\mathrm{r}}$ (Schertzer and Lovejoy, 1987; Over and Gupta, 1996; Schmitt et al., 1998; Langousis and Veneziano, 2007; Langousis et al., 2009). In this case, $Y_{\mathrm{r}}$ has a concentrated mass at zero $P\left[Y_{\mathrm{r}}=0\right]=1-r^{-C_{\beta}}$ and $\ln \left[Y_{\mathrm{r}} \mid Y_{\mathrm{r}}>0\right]$ follows a 
normal distribution with mean $\mu=-C_{\ln } \ln r$ and variance $\sigma^{2}=2 C_{\ln } \ln r$. The parameter $C_{\beta}$ controls the alternation of wet and dry intervals inside $A_{\max }$, whereas $C_{\ln }$ is responsible for the intensity fluctuations inside rainy regions; see e.g. Langousis et al. (2009).

Several empirical studies (Over and Gupta, 1996; Kundu and Bell, 2003; Deidda et al., 2004, 2006; Gebremichael et al., 2006) have shown that spatial rainfall scales in an approximately multifractal way for areas $A$ from 4$4000 \mathrm{~km}^{2}$, with values of $C_{\beta}$ that vary from $0.2-0.3$ for areas $4 \mathrm{~km}^{2} \leq A \leq 256 \mathrm{~km}^{2}$ (Kundu and Bell, 2003) and from 0.30.6 for $256 \mathrm{~km}^{2} \leq A \leq 4096 \mathrm{~km}^{2}$ (Over and Gupta, 1996; Deidda et al., 2004, 2006; Gebremichael et al., 2006); see also the review in Veneziano and Langousis (2010). Based on the multifractal model in Eq. (10), one obtains

$P[I(t)=0 \mid \bar{I}(t)>0]=P\left[Y_{\mathrm{r}}=0\right]=1-r^{-C_{\beta}}$,

and Eq. (9) simplifies to

$\bar{P}_{0}=1-\frac{1-P_{0}}{r^{-C_{\beta}}}$.

Given the aforementioned $C_{\beta}$ ranges, for small catchments (i.e. $4 \mathrm{~km}^{2} \leq A \leq 256 \mathrm{~km}^{2}$, as is the case for the Glafkos basin) the value of $C_{\beta}$ can be set to a constant $\approx 0.25$. For medium- and large-sized catchments (i.e. $256 \mathrm{~km}^{2} \leq A \leq 4096 \mathrm{~km}^{2}$ ) the value of $C_{\beta}$ can be taken to increase $\log -\log$ linearly with $A$ from $0.3-0.6$. In what follows, we propose a theoretical approach to obtain estimates of the resolution $r$ in Eq. (12).

\subsection{Linking the resolution $r$ in Eq. (12) to the shape and size of the catchment and the characteristics of storms}

Define $\theta$ to be the direction of motion of rainfall-generating features (see Fig. 10), and denote by $L_{\mathrm{c}}$ the characteristic linear dimension of the catchment. For regularly shaped catchments $L_{\mathrm{c}} \propto \sqrt{A}$, whereas for highly elongated catchments $L_{\mathrm{c}}$ can be taken proportional to their largest linear dimension (Veneziano and Langousis, 2005a). As rainfall features propagate in space and evolve in time, a rain gauge located at point $\Phi$ samples rainfall along line $\varepsilon$ (see Fig. 10). Note, however, that only line segment $\overline{\mathrm{B} \Gamma}=x(\theta)$ falls inside the basin. Consequently, for a storm moving along line $\varepsilon$, the characteristic linear sampling dimension of the rain gauge is

$L(z)=\min \left[x(\theta), v_{\mathrm{ad}} d_{\mathrm{L}}\right]$,

where $z=\left[\theta, v_{\mathrm{ad}}, d_{\mathrm{L}}\right]^{T}$ is the vector of meteorological variables that characterize the storm, and $v_{\mathrm{ad}}$ and $d_{\mathrm{L}}$ are the advection velocity and lifetime of rainfall-generating features. Indicative ranges of values for $v_{\mathrm{ad}}$ and $d_{\mathrm{L}}$ for different types of rainfall-generating features are given in Table 8; see Austin and House (1972), Orlanski (1975), Martin and Schreiner (1981), Kawamura et al. (1996), Deidda (2000), Veneziano and Langousis (2005a), and the review in Langousis (2005).

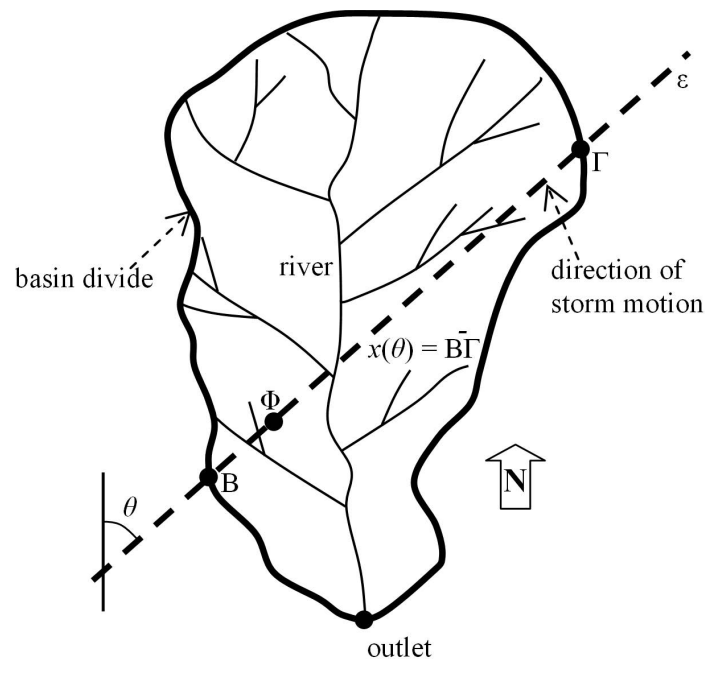

Fig. 10. Schematic illustration of the variables in Eq. (13), for a storm moving over a catchment at direction $\theta$; see main text for details.

Equation (13) directly accounts for the effects of (a) the location of the rain gauge $\Phi$ inside the basin and (b) the lifetime $d_{\mathrm{L}}$ and advection velocity $v_{\mathrm{ad}}$ of rainfall-generating features on the characteristic sampling length $L$. In the case when the joint distribution $f_{z}(z)$ of the vector $z=\left[\theta, v_{\mathrm{ad}}, d_{\mathrm{L}}\right]^{T}$ of meteorological variables is known or can be calculated from data, the expected linear sampling dimension of rain gauge $\Phi$ is obtained as

$\bar{L}=\int_{\text {all } z} f_{z}(z) L(z) \mathrm{d} z$.

Examples of the calculation of similar expectations can be found in Langousis and Veneziano (2009), for the special case of tropical cyclones.

In the case when no meteorological data are available, one can assume a uniform distribution for $\theta$ in the interval $[0$, $2 \pi$ ], estimate $d_{\mathrm{L}}$ from rainfall data as the average duration of wet periods, and use $d_{\mathrm{L}}$ to obtain a value for $v_{\mathrm{ad}}$ from Table 8. Under these assumptions, Eq. (14) reduces to

$\bar{L}=\frac{1}{2 \pi} \int_{0}^{2 \pi} L\left(\theta, v_{\mathrm{ad}}, d_{\mathrm{L}}\right) \mathrm{d} \theta$,

where $L\left(\theta, v_{\mathrm{ad}}, d_{\mathrm{L}}\right)$ is given by Eq. (13). The resolution $r$ in Eq. (12) is calculated as $r=\left(A / A_{0}\right)=\left(L_{c} / \bar{L}\right)^{2}$, where $\bar{L}$ can be obtained from Eqs. (14) or (15).

In Appendix A, we derive an analytical expression for Eq. (15) for regularly shaped catchments approximated as discs with diameter equal to their characteristic linear dimension $L_{\mathrm{c}}$. Table 9 shows estimates of $d_{\mathrm{L}}, \bar{L}$ and $r$ for locations A, B and C (see Fig. 2), using the suggested approximation. In our calculations the Glafkos catchment has linear dimension $L_{\mathrm{c}}=2 \sqrt{A / \pi}=9.14 \mathrm{~km}$, points $\mathrm{A}(\mathrm{HP})$ and $\mathrm{B}$ 
Table 9. Estimates of the average lifetime of rainfall features, $d_{\mathrm{L}}$, the average sampling length, $(\bar{L})$ (see Eqs. 15 and A.3), and the resolution $r$ (see Eq. 12), for locations A (HP), B (dam) and C (Moira); see Fig. 2. The last row of the table shows estimates of the interannual multiplicative correction factor obtained from Eq. (21).

\begin{tabular}{llll}
\hline Variable & $\begin{array}{l}\text { HP } \\
(181 \mathrm{~m} \text { a.m.s.l. })\end{array}$ & $\begin{array}{l}\text { Dam } \\
(340 \mathrm{~m} \text { a.m.s.l. })\end{array}$ & $\begin{array}{l}\text { Moira } \\
(840 \mathrm{~m} \text { a.m.s.l. })\end{array}$ \\
\hline$d_{\mathrm{L}}$ & 1.96 days & 1.97 days & 2.06 days \\
$L_{\mathrm{c}}$ & $9.14 \mathrm{~km}$ & $9.14 \mathrm{~km}$ & $9.14 \mathrm{~km}$ \\
$L$ & $5.82 \mathrm{~km}$ & $5.82 \mathrm{~km}$ & $9.14 \mathrm{~km}$ \\
$r$ & 2.47 & 2.47 & 1 \\
$h$ & 1.16 & 1.08 & 0.86 \\
\hline
\end{tabular}

(dam) are taken to be located approximately at the basin divide (i.e. the circumference of the disc; see Eq. A.3 in Appendix $\mathrm{A}$ ), and point $\mathrm{C}$ (Moira) at the centroid of the basin (i.e. the center of the disc). The resolution $r$ in Table 9 is used in Eq. (12) with $C_{\beta}=0.25$ (see discussion under Eq. 12) to calculate the number of additional wet days, needed in each month of the corrected time series (obtained in Sect. 3), to match the expected fraction of wet intervals in spatial rainfall averages. Additional wet days are prescribed starting from the largest value of the ratio $\omega$ in each month of the record and moving to smaller values till either the number of additional wet days is reached or $\omega \leq 0$.

\section{Multiplicative correction for the annual rainfall depth}

In Sect. 3 we developed a methodology to identify and resolve incompatibilities between daily rainfall measurements $I(t)$ at a point and river discharges $Q(t)$ at the outlet of the catchment, and in Sect. 4 we used concepts from multifractal theory to relate the fraction of wet intervals in point rainfall to that in spatial rainfall averages. In this way we corrected the record of point rainfall measurements $I(t)$ for incompatibilities with river discharges at the outlet of the basin and, also, adjusted the resulting rainfall time series to exhibit the fraction of dry days outlined by multifractal theory for spatial rainfall averages, $\bar{I}(t)$, over the catchment. This was done without altering the distribution of daily rainfall intensities on wet days (i.e. $\left[I_{\text {adj }}(t) \mid I_{\text {adj }}(t)>0\right] \stackrel{\mathrm{md}}{=}[I(t) \mid I(t)>0]$, where $I_{\text {adj }}(t)$ denotes the adjusted rainfall time series and $\stackrel{\mathrm{md}}{=}$ denotes equality of the marginal distributions).

Maintaining the same marginal distribution for point rainfall measurements and spatial rainfall averages on wet days would correspond to a spatially homogeneous rainfall intensity field. However, orographic effects might cause the distribution of spatial rainfall averages to deviate somewhat from that of point rainfall measurements. Several studies (see Pathinara and Herath, 2002; Badas et al., 2005; and Deidda et al., 2006) have shown that orography does not affect the statistical structure of rainfall time series (i.e. alternation of

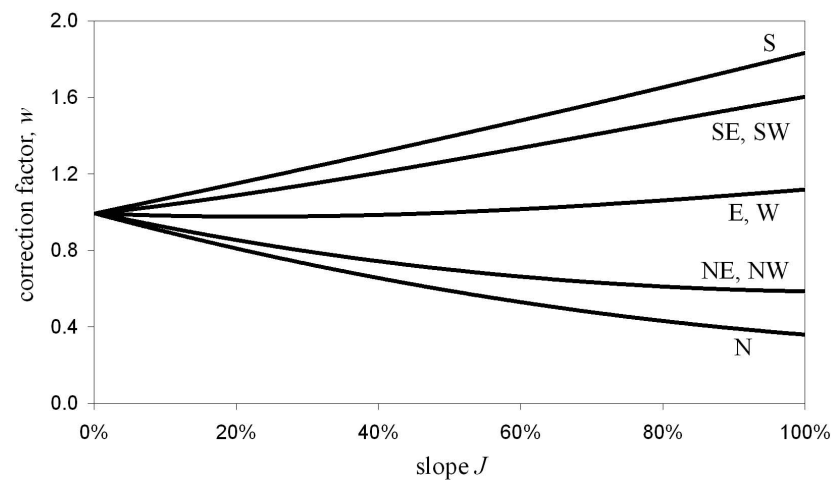

Fig. 11. Correction factor $w$ for the actual evapotranspiration $\mathrm{ET}_{\mathrm{act}}$ calculated for flat catchments, as a function of the mean slope of the basin and its orientation (N: north, S: south, E: east; W: west); adapted from DVWK (1996).

wet and dry intervals, fraction of dry days, etc.) and, hence, rainfall at different elevations can be modeled by multiplying a spatially homogeneous rainfall intensity field by a smooth increasing function of the elevation; see Badas et al. (2005) and the review in Veneziano and Langousis (2010). This is equivalent to multiplying the adjusted rainfall intensity series, $I_{\text {adj }}(t)$, by a constant multiplicative correction factor $h$. In this case,

$\bar{I}(t) \stackrel{\mathrm{d}}{\approx} \hat{\bar{I}}(t)=h I_{\mathrm{adj}}(t)$,

where $\hat{\bar{I}}$ is the suggested estimate for spatial rainfall and $\stackrel{\mathrm{d}}{\approx}$ denotes approximate equality in distributions. In what follows, we propose a semi-theoretical approach to estimate $h$ in the absence of rainfall measurements at multiple locations inside the catchment.

Define $V_{l}$ to be the annual rainfall volume reaching the catchment in year $l=1,2, \ldots$, and denote by $\mathrm{RO}_{l}$ the annual river discharge volume at the outlet of the basin in the same year. In the absence of groundwater inflows from adjacent catchments (see Introduction), the water budget equation is written, at an annual time scale, as

$V_{l}=\mathrm{RO}_{l}+w \mathrm{ET}_{\text {act }, l} A+\Delta S_{l}, \quad l=1,2, \ldots$,

where $A$ is the area of the basin, $\mathrm{ET}_{\mathrm{act}, l}$ is the actual annual evapotranspiration height in year $l$ for a flat catchment (see Eq. 18 below), $w$ is a correction factor that accounts for the effects of the mean slope $J$ of the catchment and its orientation $\varphi$ on $\mathrm{ET}_{\text {act }}$ (see below), and $\Delta S_{l}$ is the change in the subsurface storage in year $l$.

Figure 11 shows how the correction factor $w$ varies with $\varphi$ and $J$. For the catchment of the Glafkos river, which exhibits a significant mean slope of about $30 \%$ (see Table 2) facing northwest, $w \approx 0.8$.

Estimates of $\mathrm{ET}_{\mathrm{act}}$ can be obtained using semi-empirical relationships, as functions of the annual precipitation depth 
$\bar{P}$ and the mean annual temperature $\bar{T}$ or the potential evapotranspiration $\mathrm{ET}_{\text {pot }}$; see e.g. Shaw (1983). The latter is a function of $\bar{T}$. To check consistency of different actual evapotranspiration models (e.g. Pike and Turc), we calculated $\mathrm{ET}_{\text {act }}$ using precipitation measurements from stations $\mathrm{A}, \mathrm{B}$ and $\mathrm{C}$ and the temperature time series available for the catchment (see Sect. 2.3 and Table 7). We found that, for all years on record, the relative differences between different evapotranspiration models are below $5 \%$ and, hence, selection of a specific evapotranspiration model does not affect results. In what follows, we use the Turc model to estimate $\mathrm{ET}_{\text {act }}$,

$\mathrm{ET}_{\mathrm{act}}=\bar{P}\left[0.9+\left(\frac{\bar{P}}{300+25 \bar{T}+0.05 \bar{T}^{3}}\right)^{2}\right]^{-1 / 2}$,

since it does not require separate calculation of the potential evapotranspiration.

Summing Eq. (17) over the recorded years $l=1,2, \ldots, n$, one obtains

$\sum_{l=1}^{n} V_{l}=\sum_{l=1}^{n} \mathrm{RO}_{l}+w A \sum_{l=1}^{n} \mathrm{ET}_{\mathrm{act}, l}+\sum_{l=1}^{n} \Delta S_{l}$.

Assuming that the catchment does not exhibit over-year depletion of the available water resources, the annual changes in the subsurface storage should balance out over the years.

In this case $\sum_{l=1}^{n} \Delta S_{l}=0$, and Eq. (19) reduces to

$\sum_{l=1}^{n} V_{l}=\sum_{l=1}^{n} \mathrm{RO}_{l}+w A \sum_{l=1}^{n} \mathrm{ET}_{\mathrm{act}, l}$.

Using Eq. (20), an estimate of the multiplicative correction factor $h$ can be obtained as

$$
\begin{aligned}
h & =\sum_{l=1}^{n} V_{l} / \sum_{l=1}^{n}\left(A P_{\mathrm{adj}, l}\right)=\sum_{l=1}^{n} \mathrm{RO}_{l} / \sum_{l=1}^{n}\left(A P_{\mathrm{adj}, l}\right) \\
& +w \sum_{l=1}^{n} \mathrm{ET}_{\mathrm{act}, l} / \sum_{l=1}^{n} P_{\mathrm{adj}, l},
\end{aligned}
$$

where $P_{\mathrm{adj}, l}$ is the annual rainfall depth in year $l=1, \ldots, n$ calculated using the adjusted point rainfall series $I_{\text {adj }}$, and $\mathrm{ET}_{\text {act }, l}$ is calculated from Eq. (18) using $P_{\text {adj }, l}$. Table 9 shows estimates of the multiplicative correction factor $h$ using rainfall data from stations A, B and C. One sees that the correction factors for locations $\mathrm{A}(h=1.16)$ and $\mathrm{B}(h=1.08)$ are larger than 1 , whereas for location $\mathrm{C}(h=0.86)$ it is below 1 . This means that stations A and B underestimate annual rainfall volumes (as noted in the Introduction and shown in Table 1), whereas station $\mathrm{C}$ overestimates them. The observed differences between the annual rainfall volumes measured at locations A, B and C are highly associated with the intense topography of the catchment, with more than $1500 \mathrm{~m}$ altitude change in less than $10 \mathrm{~km}$. This is further justified by the fact that the inter-annual multiplicative correction factor $h$ decreases with increasing elevation (see Table 9), as larger altitudes are associated with higher annual precipitation volumes; see e.g. Gilman (1964), Smith (1993) and Badas et al. (2005).

\section{Model application and validation}

To illustrate the use of the statistical framework presented in Sects. 3-5, Fig. 12 shows a realization of the estimated spatial rainfall series, $\hat{\bar{I}}$ (see Eq. 16), obtained using point rainfall measurements from station A (hydroelectric plant, HP) for the period 1 October 1990-30 September 1992 (same period as in Fig. 1), as well as daily discharges per unit area of the basin (solid lines) at the catchment outlet (point A in Fig. 2). Dots correspond to measured rainfall depths, empty circles to synthetic rainfall intensities assigned to dry days incompatible with observed discharges at the $95 \%$ confidence level (see Sect. 3.1 and empty circles in Fig. 3), triangles to synthetic rainfall intensities that substitute the outlier values (empty circles) in Fig. 6 (see Sect. 3.2), and diamonds to synthetic rainfall intensities assigned to additional wet days so that the resulting series match the fraction of wet intervals in spatial rainfall averages predicted by multifractal theory (see Sect. 4). Synthetic rainfall intensities are simulated randomly using a lognormal distribution model with parameters obtained from Eq. (5) and Fig. 9a. In addition, all rainfall values have been multiplied by a correction factor $h=1.16$ (see Sect. 5 and Table 9) to account for the effects of spatial heterogeneity of rainfall on the annual water budgets.

Direct comparison of Figs. 1 and 12 shows good correspondence between observed changes of the river discharge and synthetic rainfall occurrence, with synthetic rainfall events located inside wet periods of the year. Hence, artificial interruptions of prolonged dry periods are avoided. This is an important attribute of the suggested approach, since it respects the seasonal character (see e.g. Langousis and Koutsoyiannis, 2006) and the clustered nature of rainfall; see LeCam (1961), Waymire and Gupta (1981a,b,c) and the review in Koutsoyannis and Langousis (2011).

To be suitable for calibration of hydrological models and engineering applications, the proposed framework for spatial rainfall estimation should reproduce the statistics of spatial rainfall averages independent of the location of the rain gauge. Figures $13-15$ show the monthly means, standard deviations, and fraction of dry days, of the measured $(I(t)$; dotted lines) and estimated $(\hat{\bar{I}}(t)$; dashed-dotted lines) rainfall time series, for daily rainfall intensities measured at points A (HP), B (dam) and C (Moira), and compare them to those of spatial rainfall averages $(\bar{I}(t)$, solid lines; see Sect. 2.1). The statistics of spatial rainfall estimates have been calculated by ensemble averaging the results from 100 realizations of $\hat{\bar{I}}$, obtained by applying the procedure described in Sects. 3-5 

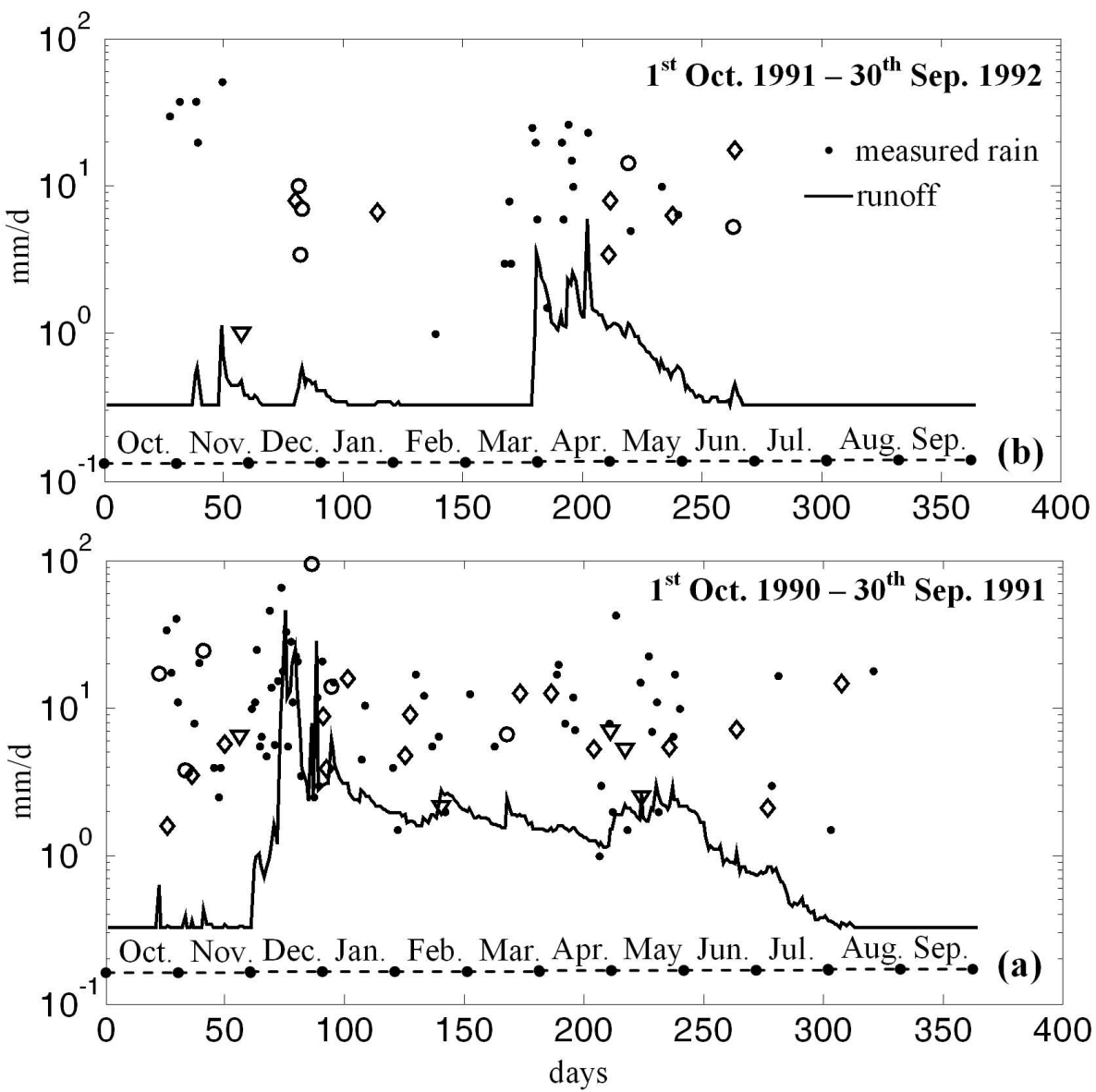

Fig. 12. Observed (dots) and simulated (empty circles, triangles and diamonds) daily rainfall intensities at the location of the hydroelectric plant (HP, point A in Fig. 2) for the period 1 October 1990-30 September 1992 (same period as in Fig. 1); see main text for details.

to point rainfall measurements from each location. Spatial rainfall averages (see Sect. 2.1) are used for validation purposes only, and do not enter the analysis at any step.

One sees that point rainfall measurements (dotted lines) from locations A (HP) and B (dam) exhibit lower monthly means and standard deviations relative to those of spatial rainfall averages (solid lines) (see Figs. 13 and 14), whereas point rainfall measurements from location C (Moira) slightly overestimate them (see Fig. 15). In addition, the fraction of dry intervals in point rainfall measurements is, in all cases, higher than that observed in spatial rainfall averages (for a justification, see Sect. 1).

Contrary to point rainfall measurements, the estimated rainfall intensities (dashed-dotted lines) reproduce well the statistics of spatial rainfall averages at a monthly time scale, independent of the location of the rain gauge, and the magnitude of the observed deviations between point rainfall measurements and spatial rainfall averages (see Figs. 13-15). The same is true, also, at an annual level.

To illustrate this, Fig. 16 shows annual rainfall totals, yearly standard deviations, and the fraction of dry days in different years, for the same rainfall series used in Fig. 13. One sees that, contrary to point rainfall measurements where the annual rainfall totals and yearly standard deviations are significantly underestimated (note that for some years on record the observed annual runoff - gray line - is higher than the corresponding rainfall volume - dotted-line; see also Introduction and Table 1), the estimated rainfall intensities match the statistics of spatial rainfall averages for all years on record. Similarly good results have been obtained, also, when using point rainfall measurements from locations B (dam) and C (Moira) (not shown here).

As noted above, the statistical framework alters the fraction of dry days in the historical record. To check whether the cross-statistics between rainfall and runoff are affected significantly by this operation, we calculated for each month the cross-correlation between daily rainfall and runoff values conditional on wet conditions (i.e. $\operatorname{corr}[Q(t), I(t) \mid I(t)>0]$ ) and the lag-1 autocorrelation of river discharges conditional on either wet (i.e. $\operatorname{corr}[Q(t), Q(t-1) \mid I(t)>0]$ ) or dry (i.e. $\operatorname{corr}[Q(t), Q(t-1) \mid I(t)=0])$ conditions. The dotted lines in Fig. 17 correspond to the historical rainfall and runoff 

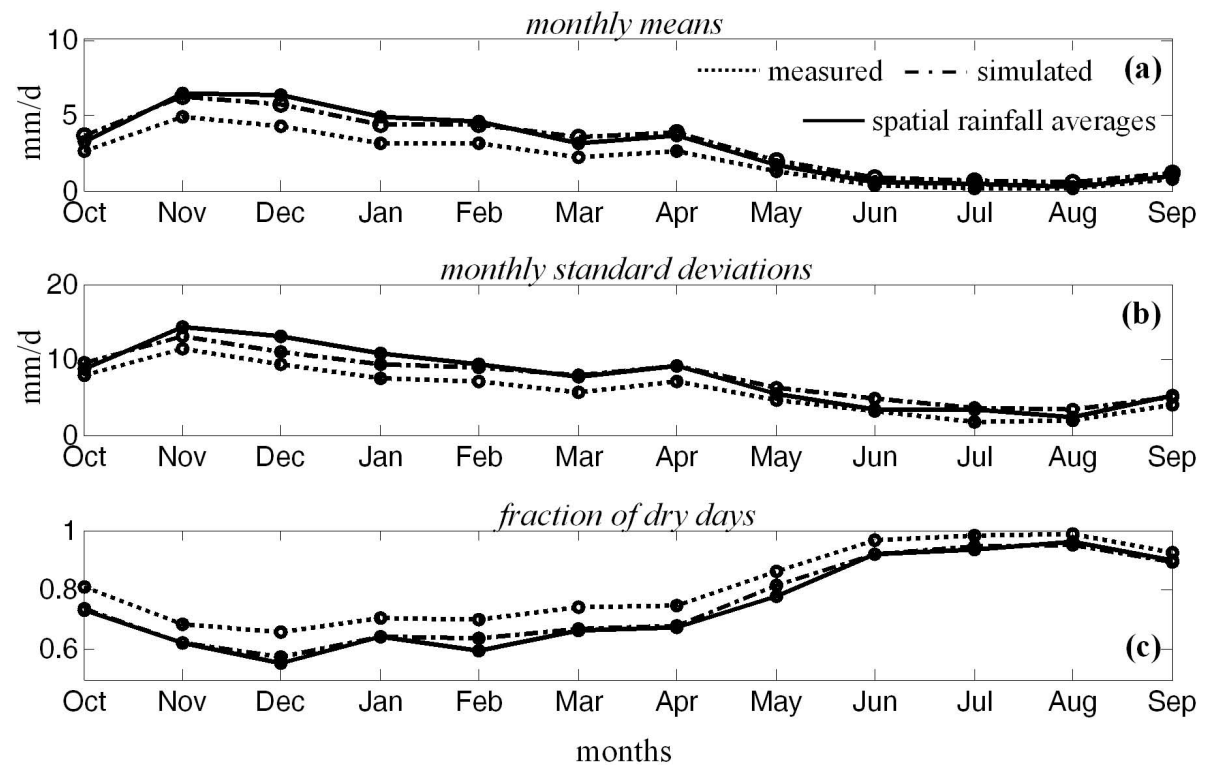

Fig. 13. Monthly means (a), standard deviations (b) and fraction of dry days (c) of the measured $(I(t)$; dotted lines) and simulated $(\hat{\bar{I}}(t)$; dashed-dotted lines) rainfall time series, obtained using daily rainfall intensities from the location of the hydroelectric plant (HP, point A in Fig. 2). The aforementioned statistics are compared with those of spatial rainfall averages $(\bar{I}(t)$; solid lines) over the catchment.
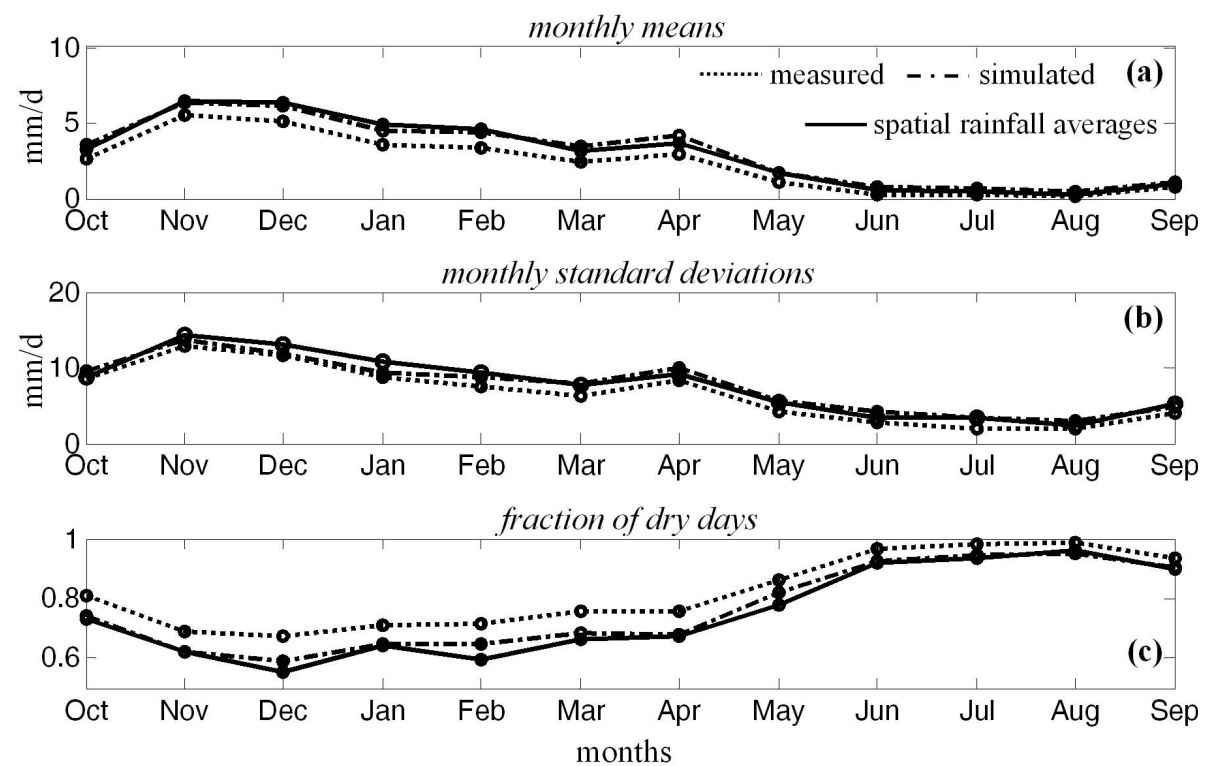

Fig. 14. Same as Fig. 13 but for the case when using point rainfall measurements from the location of the dam (point B in Fig. 2).

time series from the location of the hydroelectric plant (HP, point A in Fig. 2) and the solid lines to spatial rainfall averages, whereas the dashed lines have been obtained by ensemble averaging the results from 100 realizations of $\hat{\bar{I}}$, obtained by applying the procedure described in Sects. 3-5 to point rainfall measurements. One sees that for all months the corresponding change imposed by the statistical correction is relatively small and within the range of statistical variability. Similarly good results have been obtained when using point

Hydrol. Earth Syst. Sci., 17, 1241-1263, 2013 rainfall measurements from locations B (dam) and C (Moira) (not shown here).

\section{Discussion, comments and future developments}

For many hydrological applications, one needs accurate estimates of spatially averaged rainfall intensities. In the case of catchments covered by a single rain gauge (a frequent case for many catchments in Greece and other countries in 

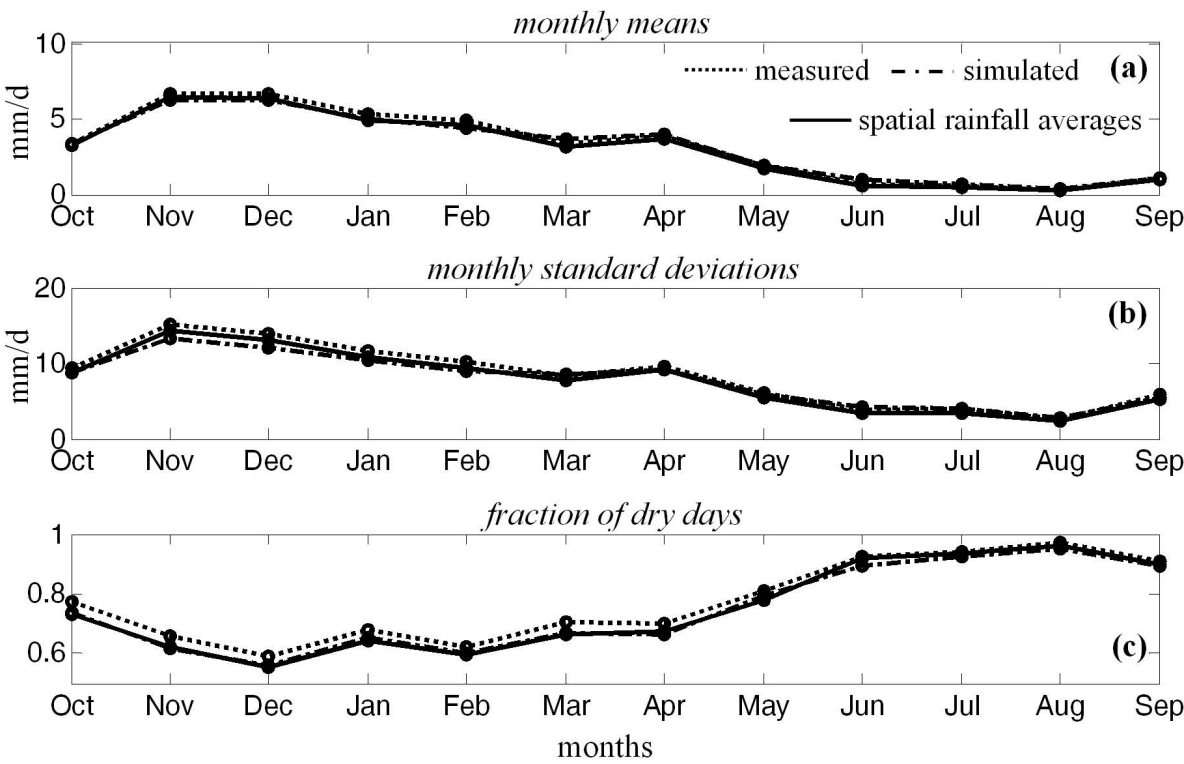

Fig. 15. Same as Fig. 14 but for the case when using point rainfall measurements from the location of Moira (point C in Fig. 2).
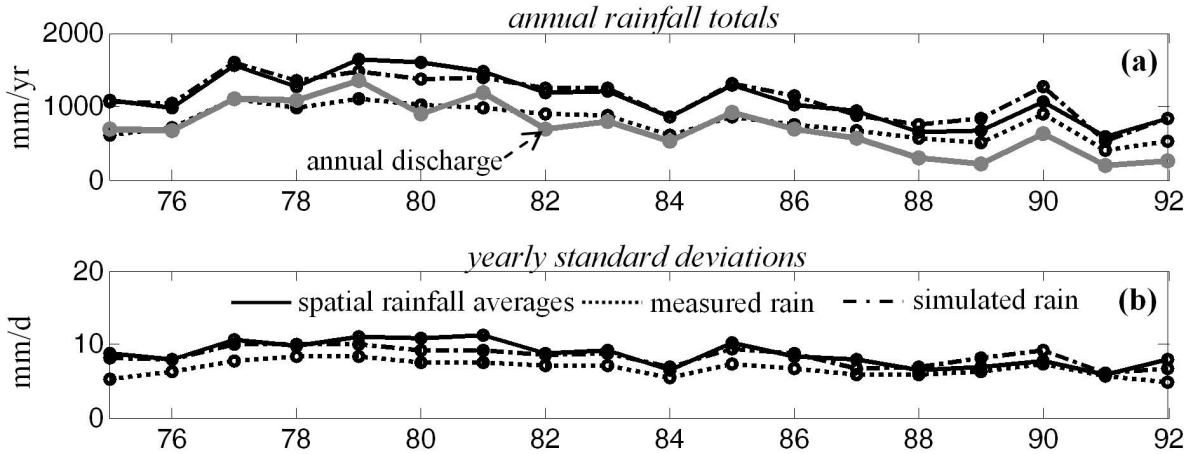

fraction of dry days

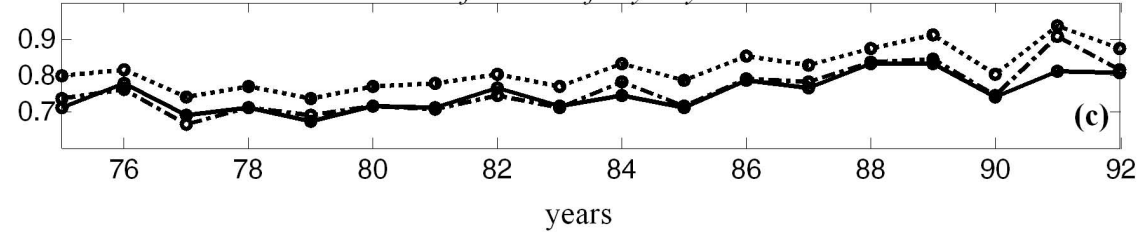

Fig. 16. Annual rainfall totals (a), yearly standard deviations (b), and fraction of dry days (c) of the measured (I $(t)$; dotted lines) and simulated $\hat{\bar{I}}(t)$; dashed-dotted lines) rainfall time series, obtained using daily rainfall intensities from the location of the hydroelectric plant (HP, point A in Fig. 2). The aforementioned quantities are compared with those of spatial rainfall averages over the catchment $(\bar{I}(t)$; solid lines). In (a), the annual discharge per unit area of the basin is shown in gray.

the Mediterranean region), one approximates spatial rainfall averages using point rainfall measurements. Since the marginal and joint statistics of the two processes are different (see Sect. 1), one faces important problems when calibrating hydrological models, calculating annual water budgets and, more importantly, when studying the impacts of climate change on river basin hydrology, the quality and availability of water resources in space and time, and the sustainability of the natural environment.
In this work, we developed a theoretical framework to obtain estimates of spatial rainfall averages over a catchment conditional on river discharges at the outlet of the basin and point rainfall measurements at a single location. This was done by developing a statistical tool that (a) identifies and corrects inconsistencies between daily rainfall occurrence and amount at the location of the rain gauge and the observed flow conditions at the outlet of the basin (Sect. 3); (b) uses concepts from multifractal theory to relate the fraction of wet 

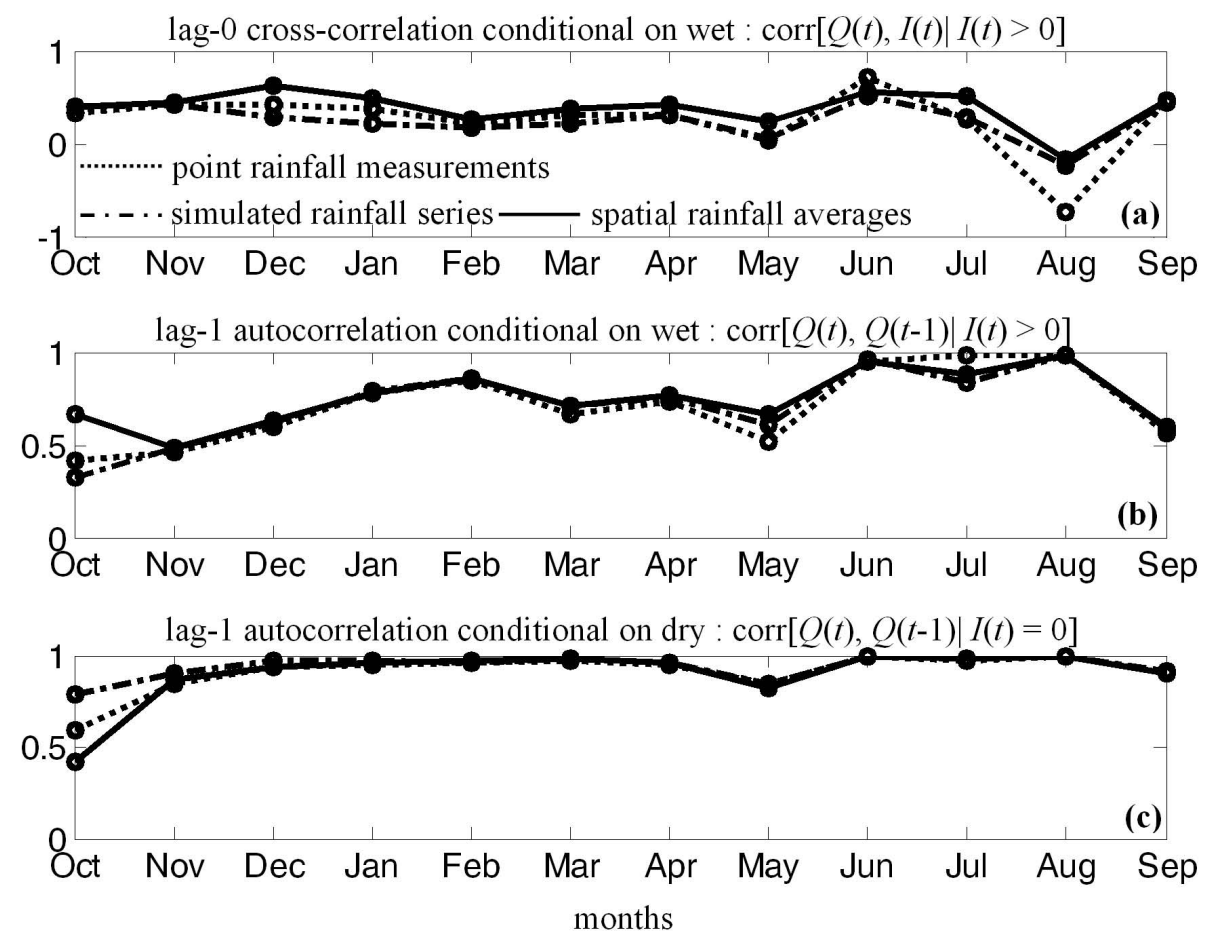

Fig. 17. (a) lag-0 cross-correlation between daily rainfall and runoff values conditional on wet conditions $\{$ i.e. $\operatorname{corr}[Q(t), I(t) \mid I(t)>0]\}$, (b) lag-1 autocorrelation of daily river discharges conditional on wet conditions (i.e. $\operatorname{corr}[Q(t), Q(t-1) \mid I(t)>0])$, (c) same as (b) but for the case of dry conditions (i.e. corr $[Q(t), Q(t-1) \mid I(t)=0])$. Dotted lines have been obtained using the historical rainfall and runoff time series at the location of the hydroelectric plant (HP, point A in Fig. 2), solid lines using the spatially averaged rainfall intensities, and dasheddotted lines have been calculated by ensemble averaging the results from 100 realizations of spatial rainfall estimates, using the procedure described in Sects. 3-5.

intervals in point rainfall to that observed in spatial rainfall averages and, also, to account for the shape and size of the basin, the characteristics of rainfall-generating features (i.e. size, lifetime and advection velocity vector), and the location of the rain gauge relative to the centroid of the basin (Sect. 4); and (c) adjusts daily rainfall intensities to resolve water budget imbalances at an inter-annual level, caused by spatial heterogeneities of rainfall due to orographic influences.

In an application study, we used point rainfall records from different locations in the Glafkos river basin and found that the suggested statistical approach efficiently identifies and resolves rainfall-runoff incompatibilities at a daily level, while respecting the seasonal character and clustered nature of rainfall. Although the statistical correction applies at a daily time scale, the method demonstrates significant skill in reproducing the statistics of spatial rainfall averages at both monthly and annual time scales, independent of the location of the rain gauge inside the basin and the magnitude of the observed deviations between point rainfall measurements and spatial rainfall averages.

The developed scheme should serve as an important tool for the effective calibration of rainfall-runoff models in basins covered by a single rain gauge and, also, improve hydrologic impact assessment at a river basin level and under changing climatic conditions. That said, several important modifications/extensions of the suggested approach should be implemented and checked.

One concerns ephemeral streams. The Glafkos river is a perennial stream with significant (non-zero) base flow in all years on record; hence, the case of zero runoff did not explicitly enter the analysis. In the case of ephemeral streams, a way to account for intermittent discharges is to include an additional category for zero previous-day runoff [i.e. $Q(t-1)=0$ ] in the statistical analysis presented in Sects. 3.1 (see Figs. 3-5) and 3.2 (see Figs. 6-8).

Another extension concerns large basins with concentrations times $t_{\mathrm{c}}$ on the order of a day or higher. In our analysis, we conditioned rainfall occurrence and amount on changes of the river discharge between two sequential days. While this is valid for small- and medium-sized catchments with concentration times of less than a day (i.e. the concentration time of the Glafkos catchment is approximately $3.5 \mathrm{~h}$; see Table 2), when dealing with catchments with concentrations times on the order of a day or higher one should extend the methodology to account for the flow conditions on several previous days. Alternatively, one can apply the same methodology to 
the rainfall and runoff time series aggregated over a timewindow that exceeds the concentration time of the basin.

Other extensions/modifications of the suggested framework include heuristic approaches for outlier identification (see Sects. 3.1 and 3.2) conditional on atmospheric variables (e.g. mean sea level pressure (MSLP), surface temperature, relative humidity, convective available potential energy (CAPE), cloud cover, etc.) and possible extensions for rainfall and runoff records with temporal resolution higher than daily. The aforementioned issues will form the subjects of future communications.

\section{Appendix A}

\section{Simple analytical approximation to Eq. (15) for regularly} shaped catchments

To simplify the analysis, one can approximate a regularly shaped catchment by a disc with diameter $L_{\mathrm{c}}=2 \sqrt{A / \pi}$, where $A$ is the area of the catchment. In the case when the average lifetime $d_{\mathrm{L}}$ of rainfall-generating features exceeds their travel-time over the basin (i.e. $d_{\mathrm{L}}>L_{\mathrm{c}} / v_{\mathrm{ad}}$, where $v_{\mathrm{ad}}$ is the advection velocity; see Sect. 4.1), Eq. (13) reduces to

$$
L(z)=L(\theta)=\overline{\mathrm{B} \Gamma}=2 \sqrt{\left(L_{\mathrm{c}} / 2\right)^{2}-(x \sin \theta)^{2}}, \quad 0 \leq \theta \leq 2 \pi,
$$

where $\theta$ is the direction of storm motion and $x=\overline{\Phi O} \leq L_{\mathrm{c}} / 2$ is the distance of the rain gauge from the centroid of the basin (i.e. the center of the disk) (see Fig. A1).

Using an indicative advection velocity on the order of 20 $30 \mathrm{~km} \mathrm{~h}^{-1}$ (see Table 8), Eq. (A1) is valid for small- and medium-sized catchments in subtropical regions, where rainfall is dominated by formations with lifetimes, $d_{\mathrm{L}}$, on the order of several hours or more.

Assuming a uniform distribution for $\theta$ and combining Eqs. (A1) and (15), one obtains

$\bar{L}=\frac{1}{\pi} \int_{0}^{2 \pi} \sqrt{\left(L_{\mathrm{c}} / 2\right)^{2}-(x \sin \theta)^{2}} \mathrm{~d} \theta$.

Based on symmetry arguments for the integrated function, Eq. (A2) can be written as

$\bar{L}=\frac{2 L_{\mathrm{c}}}{\pi} K_{\mathrm{c}}\left(4 x^{2} / L_{\mathrm{c}}^{2}\right)$,

where $K_{\mathrm{c}}(y)=\int_{0}^{\pi / 2} \sqrt{1-y \sin ^{2} \theta} \mathrm{d} \theta$ is the complete elliptic integral of the second kind. For a rain gauge located at the circumference of the disc (i.e. the basin divide; $x=L_{\mathrm{c}} / 2$ ), Eq. (A3) gives $\bar{L}=2 L_{\mathrm{c}} / \pi$, whereas for a rain gauge located at the centroid of the basin (i.e. the center of the disk; $x=0$ ) $\bar{L}=L_{\mathrm{c}}$.

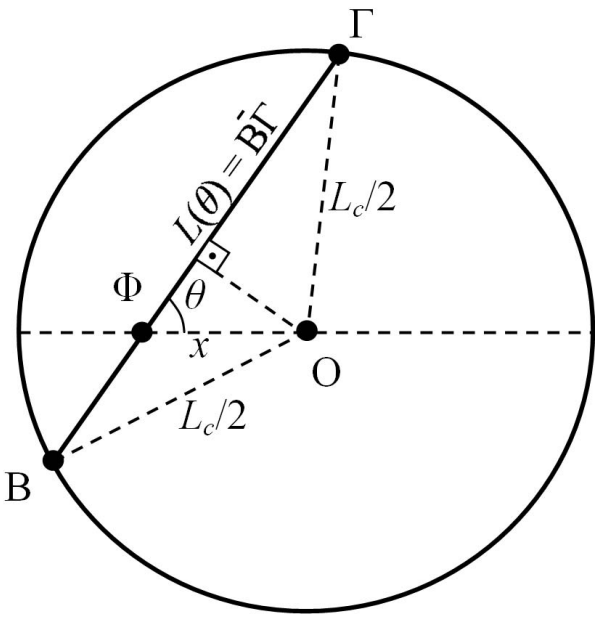

Fig. A1. Schematic illustration of a regularly shaped catchment approximated by a disc with characteristic linear dimension (diameter) $L_{\mathrm{c}}$. The rain gauge is located at point $\Phi$.

Acknowledgements. The research project is implemented within the framework of the Action "Supporting Postdoctoral Researchers" of the Operational Program "Education and Lifelong Learning" (Action's Beneficiary: General Secretariat for Research and Technology), and is co-financed by the European Social Fund (ESF) and the Greek State. In addition, the second author would like to acknowledge the financial support of Helmholtz-Zentrum fuer Umweltforschung GmbH - UFZ (contract: UFZ-02/2009 (RA-3205/09)). The constructive comments and suggestions of two anonymous reviewers are highly appreciated.

Edited by: R. Deidda

\section{References}

Atkinson, A. C.: Two graphical displays for outlying and influential observations in regression, Biometrika, 68, 13-20, 1981.

Austin, P. M. and House, R. A.: Analysis of the structure of precipitation patterns in New England, J. Appl. Meteorol., 11, 926-935, 1972.

Badas, M. G., Deidda, R., and Piga, E.: Orographic influences in rainfall downscaling, Adv. Geosci., 2, 285-292, doi:10.5194/adgeo-2-285-2005, 2005.

Banerjee, S., Carlin, B. P., and Gelfand, A. E.: Hierarchical Modeling and Analysis for Spatial Data, Chapman and Hall/CRC Press, Taylor and Francis Group, 2004.

Belsley, D. A., Kuh, E., and Welsch, R. E.: Regression Diagnostics: Identifying Influential Data and Sources of Collinearity, Wiley, New York, 1980.

Chatterjee, S. and Hadi, A. S.: Influential Observations, High Leverage Points, and Outliers in Linear Regression, Stat. Sci., 1, 379416, 1986.

Cheng, M. and Qi, Y.: Frontal rainfall-rate distribution and some conclusions on the threshold method, J. Appl. Meteorol., 41, 1128-1139, 2002. 
Cho, H. K., Bowman, K. P., and North, G. R.: A comparison of gamma and lognormal distributions for characterizing satellite rain rates from the tropical rainfall measuring mission, J. Appl. Meteorol., 43, 1586-1597, 2004.

Chow, V. T.: Runoff, in: Handbook of Applied Hydrology, Sect. 14, edited by: Chow, V. T., McGraw-Hill, USA, 14-1-14-54, 1964.

Chow, V. T., Maidment, D. R., and Mays, L.W .: Applied Hydrology, McGraw-Hill, New York, 1988.

Deidda, R.: Rainfall downscaling in a space-time multifractal framework, Water Resour. Res., 36, 1779-1794, 2000.

Deidda, R., Badas, M. G., and Piga, E.: Space-time scaling in high-intensity tropical ocean global atmosphere coupled oceanatmosphere response experiment (TOGA-COARE) storms, Water Resour. Res., 40, W02506, doi:10.1029/2003WR002574, 2004.

Deidda, R., Grazia-Badas, M., and Piga, E.: Space-time multifractality of remotely sensed rainfall fields, J. Hydrol., 322, 2-13, doi:10.1016/j.jhydrol.2005.02.036, 2006.

Dingman, S. L.: Physical Hydrology, 2nd Edn., Prentice-Hall, USA, p. 441, 2002.

DVWK: Ermittlung der Verdunstung von Land- und Wasserflaechen, Merkblatt 238, Wirtschafts- und Verlagsgesellschaft Gas und Wasser mbH, Bonn, 1996.

Eagleson, P. S.: Dynamic Hydrology, McGraw-Hill, New York, 1970.

Eleuch, S., Carsteanu, A., Bâ, K., Magagi, R., Goïta, K., and Diaz, C.: Validation and use of rainfall radar data to simulate water flows in the Rio Escondido basin, Stoch. Environ. Res. Risk A., 24, 559-565, doi:10.1007/s00477-009-0336-9, 2010.

Gebremichael, M. and Krajewski, W. F.: Assessment of the statistical characterization of small-scale rainfall variability from radar: Analysis of TRMM ground validation datasets, J. Appl. Meteorol., 43, 1180-1199, 2004.

Gebremichael, M., Over, T. M., and Krajewski, W. F.: Comparison of the scaling properties of rainfall derived from space- and surface-based radars, J. Hydrometeorol., 7, 1277-1294, 2006.

Gilman, C. S.: Rainfall, in: Handbook of Applied Hydrology, Sect. 9, edited by: Chow, V. T., McGraw-Hill, USA, 9-1-9-68, 1964.

Gupta, V. K. and Waymire, E. C.: A statistical analysis of mesoscale rainfall as a random cascade, J. Appl. Meteorol, 32, 251-267, 1993.

Hutchinson, P.: A contribution to the problem of spacing raingauges in rugged terrain, J. Hydrol., 12, 1-14, 1970.

Isaaks, E. H. and Srivastava, R. M.: An Introduction to Applied Geostatistics, Oxford University Press, New York, 561 pp., 1989.

Journel, A. G. and Huijbregts, C. J.: Mining Geostatistics, Academic Press, London, 1978.

Kaleris, V. and Ziogas, A.: Evaluation of available data for water budget calculations in the Glafkos catchment, Western Greece, Report for the contract UFZ-02/2099 (RA-3205/09), Hydraulic Engineering Laboratory, University of Patras, Greece, 2011.

Kaleris, V., Papanastasopoulos, D., and Lagas, G.: Case study on impact of atmospheric circulation changes on river basin hydrology: uncertainty aspects, J. Hydrol., 245, 137-152, 2001.

Kawamura, A., Jinno, K., Berndtsson, R., and Furukawa, T.: Parameterization of rain cell properties using an advection-diffusion model and rain gage data, Atmos. Res., 42, 67-73, 1996.
Kedem, B., Chiu, L. S., and Karni, Z.: An analysis of the threshold method for measuring area-average rainfall, J. Appl. Meteorol., 29, 3-20, 1990a.

Kedem, B., Chiu, L. S., and North, G. R.: Estimation of mean rain rate: Application to satellite observations, J. Geophys. Res., 95, 1965-1972, 1990b.

Kedem, B., Pfeiffer, R., and Short, D. A.: Variability of space-time mean rain rate, J. Appl. Meteorol., 36, 443-451, 1997.

Koutsoyiannis, D. and Langousis, A.: Precipitation, in: Treaties on Water Sciences: Hydrology, Vol. 2, edited by: Wilderer, P. and Uhlenbrook, S.,Academic Press, Oxford, 27-78, 2011.

Krige, D. G.: A statistical approach to some mine valuations and allied problems at the Witwatersrand, MSc thesis of the University of Witwatersrand, 1951.

Kundu, P. K. and Bell, T. L.: A stochastic model of space-time variability of mesoscale rainfall: Statistics of spatial averages, Water Resour. Res., 39, 1328, doi:10.1029/2002WR001802, 2003.

Langousis, A.: The Areal Reduction Factor a Multifractal Analysis, MSc Thesis, Department of Civil and Env. Eng., MIT, Cambridge, MA, USA, 1-117, 2005.

Langousis, A. and Koutsoyiannis, D.: A stochastic methodology for generation of seasonal time series reproducing over-year scaling behavior, J. Hydrol., 322, 138-154, 2006.

Langousis, A. and Veneziano, D.: Intensity-duration-frequency curves from scaling representations of rainfall, Water Resour. Res., 43, W02422, doi:10.1029/2006WR005245, 2007.

Langousis, A. and Veneziano, D.: Long-term rainfall risk from Tropical Cyclones in coastal areas, Water Resour. Res., 45, W11430, doi:10.1029/2008WR007624, 2009.

Langousis, A., Veneziano, D., Furcolo, P., and Lepore, C.: Multifractal rainfall extremes: Theoretical analysis and practical estimation, Chaos Solit. Fract., 39, 1182-1194, doi:10.1016/j.chaos.2007.06.004, 2009.

LeCam, L.: A stochastic description of precipitation, in: Proceedings of Fourth Berkeley Symposium on Mathematical Statistics and Probability, vol. 3, edited by: Neyman, J., Univ. of Calif. Press, Berkeley, 165-176, 1961.

Lettenmaier, D. P. and Wood, E. F.: Hydrologic forecasting, in: Handbook of Applied Hydrology, Ch. 26, edited by: Maidment, D. A., McGraw-Hill, New York, 26.1-26.30, 1993.

Loukas, A. and Quick, M. C.: Physically-based estimation of lag time for forested mountainous watersheds, Hydrolog. Sci. J., 41, 1-19, 1996.

Lovejoy, S. and Schertzer, D.: Multifractals and rain, in: New Uncertainty Concepts in Hydrology and Hydrological Modelling, edited by: Kundzewicz, A. W., Cambridge Press, 1995.

Mandilaras, D.: Environmental-hydrogeological study of Glafkos river basin, Ph.D. Thesis, Laboratory of Hydrogeology, Department of Geology, University of Patras, Greece, 2005.

Martin, D. W. and Schreiner, A. J.: Characteristics of West African and East Antlantic cloud clusters: A survey from GATE, Mon. Weather Rev., 109, 1671-1688, 1981.

Nikas, K. A.: Hydrogeological conditions in Northeast Achaia, Ph.D. thesis, Department of Geology, University of Patras, Greece, 2004.

Orlanski, I.: A rational subdivision of scales for atmospheric processes, Am. Meteorol. Soc., 56, 527-530, 1975. 
Over, T. M. and Gupta, V. K.: A space-time theory of mesoscale rainfal using random cascades, J. Geophys. Res., 101, 2631926331, 1996.

Pathirana, A. and Herath, S.: Multifractal modelling and simulation of rain fields exhibiting spatial heterogeneity, Hydrol. Earth Syst. Sci., 6, 695-708, doi:10.5194/hess-6-695-2002, 2002.

Press, W. H., Teukolsky, S. A., Vetterling, W. T., and Flannery, B. P.: Interpolation by Kriging, in: Numerical Recipes: The Art of Scientific Computing, Sect. 3.7.4, 3rd Edn., Cambridge University Press, New York, 2007.

Schertzer, D. and Lovejoy, S.: Physical modeling and analysis of rain and clouds by anisotropic scaling of multiplicative processes, J. Geophys. Res., 92, 9693-9714, 1987.

Schmitt, F., Vannistem, S., and Barbosa, A.: Modeling of rainfall time series using two-state renewal processes and multifractals, J. Geophys. Res., 103, 23181-23193, 1998.

Shaw, E. M.: Hydrology in Practice, Van Nostrand Reinhold, UK, 1983.

Shimizu, K.: A bivariate mixed lognormal distribution with an analysis of rainfall data, J. Appl. Meteorol., 32, 161-171, 1993.

Shoji, T. and Kitaura, H.: Statistical and geostatistical analysis of rainfall in central Japan, Comput. Geosci., 32, 1007-=1024, 2006.

Singh, V. P.: Elementary Hydrology, Prentice-Hall, New Jersey, USA., 1992.

Smith, J. A.: Precipitation, in: Handbook of Applied Hydrology, Ch. 3, edited by: Maidment, D. A., McGraw-Hill, New York, 3.1-3.47, 1993 .

Smith, R. B.: The influence of mountains on the atmosphere, Adv. Geophys., 21, 87-230, 1979.

Suhaila, J. and Jemain, A. A.: Fitting daily rainfall amount in Malaysia using the normal transform distribution, J. Appl. Sci., 7, 1880-1886, 2007.

Thiessen, A. H.: Precipitation for large areas, Mon. Weath. Rev., 19, 1082-1084, 1911.

US Army Corps of Engineers: Sacramento method of correlating storm precipitations with normal seasonal precipitations and runoff, US Army Corps of Engineers Rept., Sacramento District Office, 1941.

Velleman, P. F. and Welsch, R. E.: Efficient computing of regression diagnostics, Am. Stat., 23, 27-31, 1981.

Veneziano, D.: Basic properties and characterization of stochastically self-similar processes in $R^{\mathrm{D}}$, Fractals, 7, 59-78, 1999.
Veneziano, D. and A. Langousis, A.: The areal reduction factor a multifractal analysis, Water Resour. Res., 41, W07008, doi:10.1029/2004WR003765, 2005a.

Veneziano, D. and Langousis, A.: The maximum of multifractal cascades: Exact distribution and approximations, Fractals, 13, 311324, 2005b.

Veneziano, D. and Langousis, A.: Scaling and fractals in hydrology, in: Advances in Data-based Approaches for Hydrologic Modeling and Forecasting, edited by: Sivakumar, B. and Berndtsson, R., World Scientific, p. 145, 2010.

Veneziano, D., Langousis, A., and Furcolo, P.: Multifractality and rainfall extremes: A review, Water Resour. Res., 42, W06D15, doi:10.1029/2005WR004716, 2006.

Veneziano, D., Lepore, C., Langousis, A., and Furcolo, P.: Marginal methods of intensity-duration-frequency estimation in scaling and nonscaling Rainfall, Water Resour. Res., 43, W10418, doi:10.1029/2007WR006040, 2007.

Voudouris, K.: Hydrogeological conditions in Northwest Achaia, Ph.D. Thesis, Department of Geology, University of Patras, Greece, 1995.

Watt, W. E. and Chow, K. C. A.: A general expression for basin lag time, Can. J. Civ. Eng., 12, 294-300, 1985.

Waymire, E. and Gupta, V. K.: The mathematical structure of rainfall representations, 1 . A review of the stochastic rainfall models, Water Resour. Res., 17, 1261-1272, 1981a.

Waymire, E. and Gupta, V. K.: The mathematical structure of rainfall representations, 2. A review of the theory of point processes, Water Resour. Res., 17, 1273-1285, 1981b.

Waymire, E. and Gupta, V. K.: The mathematical structure of rainfall representations, 3. Some applications of the point process theory to rainfall processes, Water Resour. Res., 17, 1287-1294, 1981c.

Wilby, R. L., Orr, H. G., Hedger, M., Forrow, D., and Blackmore, M.: Risks posed by climate change to the delivery of the Water Framework Directive objectives in the UK, Environ. Int., 32, 1043-1055, 2006

Willmott, C. J., Robeson, S. M., and Feddema, J. J.: Estimating continental and terrestrial precipitation averages from rain-gauge networks, Int. J. Climatol., 14, 403-414, doi:10.1002/joc.3370140405, 1994.

Ziogas, A.: Water budget of Glafkos aquifer and estimation of the capture zone of pumping wells, M.Sc. Thesis, Hydraulic Engineering Laboratory, Department of Civil Engineering, University of Patras, Greece, 2006. 